\title{
OSMANISCHE SPRICHWÖRTER (1865) ADLI ESERDEKİ TÜRK ATASÖZLERİ VE BU ATASÖZLERININN TELAFFUZU -II-
}

\author{
TURKISH PROVERBS AND THEIR PRONUNCIATION IN \\ OSMANISCHE SPRICHWÖRTER (1865) -II-
}

Tuncay BÖLER*

\begin{abstract}
$\ddot{O} z$
1928 Harf İkılabi'ndan önce Avrupalı bilginler tarafindan Latin harfleriyle yazılan transkripsiyon metinleri (transcribed texts), Türk dili araştırmaları için oldukça önemlidir. Ana dili Türkçe olmayanların elinden çıkması sebebiyle birtakım yanlışları ihtiva edebileceğgi hatırdan uzak tutulmaması gereken transkripsiyon metinlerinin yazılış amaçları farklı farkl olsa da bunlar özellikle sözcüklerin telaffuzlarma yani konuşma diline de yer verdikleri için- ses bilgisi ve başka açılardan önemli birer kaynaktır. Bu türden eserler üzerinde Batı'da 1900'lü yılların başında birtakım incelemeler yapılmaya başlanmışken Türkiye'deki araştırmalar 1990'lı yıllara kadar sarkmıştır. Günümüzde Almanca, Fransızca, İtalyanca, İngilizce yazılmış birtakım transkripsiyon metinleri üzerinde yapılan çalışmalar hâlâ devam etmektedir. Burada konu edinilen atasözlerine kaynaklık eden Osmanische Sprichwörter (Osmanl Atasözleri) 1865'te Viyana'da yayımlanmış transkripsiyon metinlerindendir. Eserde 500 atasözü bulunmaktadır. Bilindiği gibi Arap alfabesi ile yazılan sözcükler genellikle kalıplaşmış bir imlaya sahip oldukları için çoğu zaman telaffuzu örter, tam olarak göstermezler. Osmanische Sprichwörter'de hem Alman ve hem de Fransız transkripsiyon sistemine göre atasözlerinin telaffuzları yazıya yansıtılmaya çalışılmış, böylelikle bizler için imla ile telaffuz arasındaki farklılıkların görülmesi imkânı ortaya çıkmıştır. Makalede Osmanische Sprichwörter'de bulunan 100 (101-200 arası) atasözü değerlendirilmiş, bu atasözlerinde yer alan sözcük ve eklerin telaffuzları ele alınmıştır.
\end{abstract}

Anahtar Kelimeler

Ses bilgisi, Telaffuz, Transkripsiyon Metinleri, Atasözü

\section{Abstract}

Transcribed texts written in Latin letters by European scholars before the Letter Revolution of 1928 are very important for Turkish studies. It should be noted that they may contain some mistakes as they are the works of non-native speakers. While these texts may have been written for other purposes, they are nonetheless significant phonological resources as they include pronunciation of words, i.e colloquial language. Studies on these type of works started in early 1900s in the West whereas they started in 1990s in Turkey. Transcribed texts written in German, French, Italian and English are currently being studied. The subject of this study is the transcribed texts of Osmanische Sprichwörter, published in 1865 in Vienna. It contains 500 proverbs. Words written in Arabic

\footnotetext{
* Doç. Dr., Tokat Gaziosmanpaşa Üniversitesi Fen-Edebiyat Fakültesi Türk Dili ve Edebiyatı Bölümü, tuncayboler@gmail.com,
} ORCID: 0000-0001-9275-7083 
alphabet mostly obscured pronunciation as they had rigid, structured orthography. In Osmanische Sprichwörter, the pronunciation of proverbs are given both in German and in French transcription systems and thereby it was made possible to ascertain the difference between orthography and pronunciation. In this study, 100 (101 to 200) proverbs were evaluated. The pronunciations of the words and affixes were discussed.

\section{Keywords}

Phonetics, Pronunciation, Transcribed Texts, Proverb 


\section{GİRIŞ}

Dilimiz için yeterince elverişli olmasa da Türkçe yaklaşık bin yıl boyunca Arap harfleriyle yazılmıştır. Bununla birlikte Türkçenin Arap harfleriyle yazımındaki elverişsizlikler yüzünden pek çok güçlükle karşılaşılmış, özellikle imlada doğan kargaşa, yüzyıllar boyunca sürmüştür (Tulum, 1991, s. 27). Bilindiği üzere Arap harfli metinlerde çoğu zaman kalıplaşmış olan imla dilin asli seslerinin ve dildeki değişimlerin izlenmesini zorlaştırmaktadır. Bu nedenle Batılılar tarafından yazılan ve "transkripsiyon metinleri" adı verilen eserler Arap harfli metinlere göre dilin seslerini daha net ortaya koyabilmeleri bakımından oldukça önemlidir. Eski imlada gösterilemeyen bazı ünlü ve ünsüz seslerin bu metinlerde açık bir şekilde görülebilmeleri k-/g-, t-/d-, o/u, ö/ü gibi seslerin belirlenmesinde de onları yegâne kaynak hâline getirmektedir (Duman, 1999, s. 72).

“Transkripsiyon metinleri” terimi Türkoloji'de Arap alfabesi dışında (Latin, Yunan, Ermeni, Süryani, İbrani, Kiril gibi) alfabelerle yazılmış Türkçe metinleri ifade etmek üzere kullanılmaktadır. Her ne kadar Hazai $(2012$, s. 31) bu terime itiraz ederek "Arap yazısı dışındaki anıtlar" şeklinde bir adlandırmanın daha doğru olduğunu ifade etse de "transkripsiyon metinleri" ya da "transkripsiyon anıtları" terimleri artık sıklıkla kullanılmaktadır. Sanki günümüz için çözümlenmiş ve yazıya geçirilmiş bir tür ses kaydı olan (Kartallığlu, 2011, s. 26) ve 1900'lü yılların başından beri özellikle Avrupalılar tarafından işlenen bu metinler ancak 1990'lı yıllardan sonra Türk araştırmacıların ilgisini çekmeye başlamış, bu ilgiyle birlikte transkripsiyon metinleri üzerinde çalışmalar yapılmıştır.

Makalede ele alınıp değerlendirilen transkripsiyon metni Osmanische Sprichwörter adlı eserdir. 1865 yılında yazılan Osmanische Sprichwörter'deki atasözleri Alman ve Fransızların okuyabilmelerine imkân sağlamak amacıyla Arap harfleri yanında Latin harfleri ile de gösterilmiştir. Böylelikle Türk dili araştırmacıları için 19. yüzyılın ikinci yarısındaki kimi sözcük ve eklerde imlanın engellediği/gizlediği telaffuzları görme imkânı ortaya çıkmıştır. Makalede Osmanische Sprichwörter hakkında bilgi verildikten sonra eserdeki atasözleri (101-200 arası) incelenmiş, sonuç bölümünde atasözlerindeki kimi sözcük ve eklerin telaffuzları değerlendirilmiştir. Amacımız Türk dilinin tarihi fonetiğine dair çalışmalara katkı sunabilmektir.

\section{Osmanische Sprichwörter (=OS, Osmanlı Atasözleri)}

Viyana Doğu Dilleri Akademisi (VDDA) öğrencileri M. Pasetti Ritter Von Friedenburg, A. Rehn, A. Bargehr, J. Günner, E. Von Sauer-Czaky-Nordendorf, E. Trechich ve direktör Ottokar Maria Freiherr von Schlechta-Wssehrd tarafından hazırlanan OS'nin yayım tarihi 1865'tir. Eserde ele alınan atasözlerinin VDDA'ya mensup iki eski öğrenci tarafından hazırlanan el yazmaları koleksiyonu ile Güvahi'ye ait el yazması esere dayandığı ön sözde ifade edilmektedir.

OS'de yer alan atasözü sayısı 500'dür. Atasözleri Arap alfabesiyle verilirken sadece ilk 250'sinde okuma işaretleri yani harekeler kullanılmış, atasözlerinin ikinci yarısında ise hareke önemsenmemiştir. Ayrıca, eserin amacı Alman ve Fransızlara Türk dilini öğretmek olduğu için böyle yapılmasında "kolaydan zora" geçiş düşüncesinin etkili olduğundan kitabın başında bahsedilmiştir. Yine OS'de belirtildiğine göre, eserde orta bir yol izlenerek hem "oryantal yazıma" yani kalıplaşmış imlaya sadık kalınmaya hem de telaffuzlar gösterilmeye çalışılmıştır. Hatta, eserde telaffuza daha fazla önem verildiğinin özellikle üzerinde durulmuştur. 
OS'nin bir başka hedefi, Alman ve Fransızlara herhangi bir öğretmene ihtiyaç duymadan Osmanlıca yazıları okuyup anlamanın başlangıçtaki zorluklarını aşabilmelerinde kolaylık sağlamaktır. Bununla birlikte eserde aynı kolaylık kendisini Almanca ve Fransızca metinler konusunda yetiştirmek isteyen Türklere de sunulmak istenmiştir. Bu çift taraflı sorumluluğu yerine getirmek için de mümkün olduğunca basit metinler seçilmiş, bu konudaki en iyi seçeneğin, atasözleri olduğu düşünülmüştür. Çünkü, atasözleri kısa ve özdürler, bununla birlikte gramer özellikleri yanında kültür ve gelenek barındırdıkları için de avantajlıdırlar.

OS' de Arap harfli metne yapılan ilaveler şunlardır:

\section{Satır Altı (Almanca ve Fransızca) Tercüme}

Arap harfli metinlerin altında atasözlerinin sözcük sözcük Almanca ve Fransızca tercümeleri verilmiştir. Bununla herhangi bir öğreticiye gereksinim duyulmadan çalışılabilmesi hedeflenmiştir. Ön sözde başka dillerde yaygın ve başarılı bir şekilde kullanılan bu metodun ilk kez (?) Batı Türkçesine ayrıntılı bir biçimde uygulandığının ifade edilmesi ilgi çekicidir.

\section{Telaffuz}

OS'de atasözlerinin Arap harfli yazımları yanında telaffuzlarına yani konuşma dilindeki biçimlerine de yer verilmiştir. Bu yapılırken biri Alman diğeri Fransız olmak üzere iki ayrı transkripsiyon sistemi kullanılmıştır. Eserde atasözlerinin ses bakımından "İstanbul'un en seçkin çevreleri"nde konuşulan dile uyarlanmaya çalışıldığının ifade edildiğini burada belirtmek gerekir.

\section{Almanca ve Fransizca Tercüme}

Burada atasözlerinin Almanca ve Fransizcaya tercümeleri verilmiştir. Bu tercüme kimi zaman atasözünün ifade ettiği anlama sahip söz konusu dillerde yer alan başka bir atasözünün verilmesi şeklinde yapılmıştır.

\section{Sözlük}

OS'nin sonunda atasözlerinde bulunan birtakım sözcüklerin Almanca ve Fransızca karşılıklarının yer aldığı bir sözlük de bulunmaktadır.

\section{OS'deki Atasözleri}

Aşağıda OS'deki 100 (101-200 arası) ${ }^{1}$ atasözü günümüzdeki biçimlerine göre alfabetik sıraya dizilerek şemada yer alan bilgiler dâhilinde verilmiştir.

Eserdeki ilk 100 atasözü tarafımızdan ele alınıp değerlendirilmiştir: Böler, T. (2018). Osmanische Sprichwörter (1865) adlı eserdeki Türk atasözleri ve bu atasözlerinin telaffuzu. V. Yıldız Uluslararası Sosyal Bilimler Kongresi Tam Metin Bildiri Kitabı içinde (s. 850-865), İstanbul: Yıldız Teknik Üniversitesi Yay. Osmanische Sprichwörter'le ilgili çalışmalarımızı devam ettirirken eser Beytullah Bekâr tarafından yapılan bir çalışmada da işlenmiştir: Bekâr, B. (2019). Batı kültüründe Türk atasözleri (16. yüzyll-19. yüzyll). Konya: Kömen Yay. 


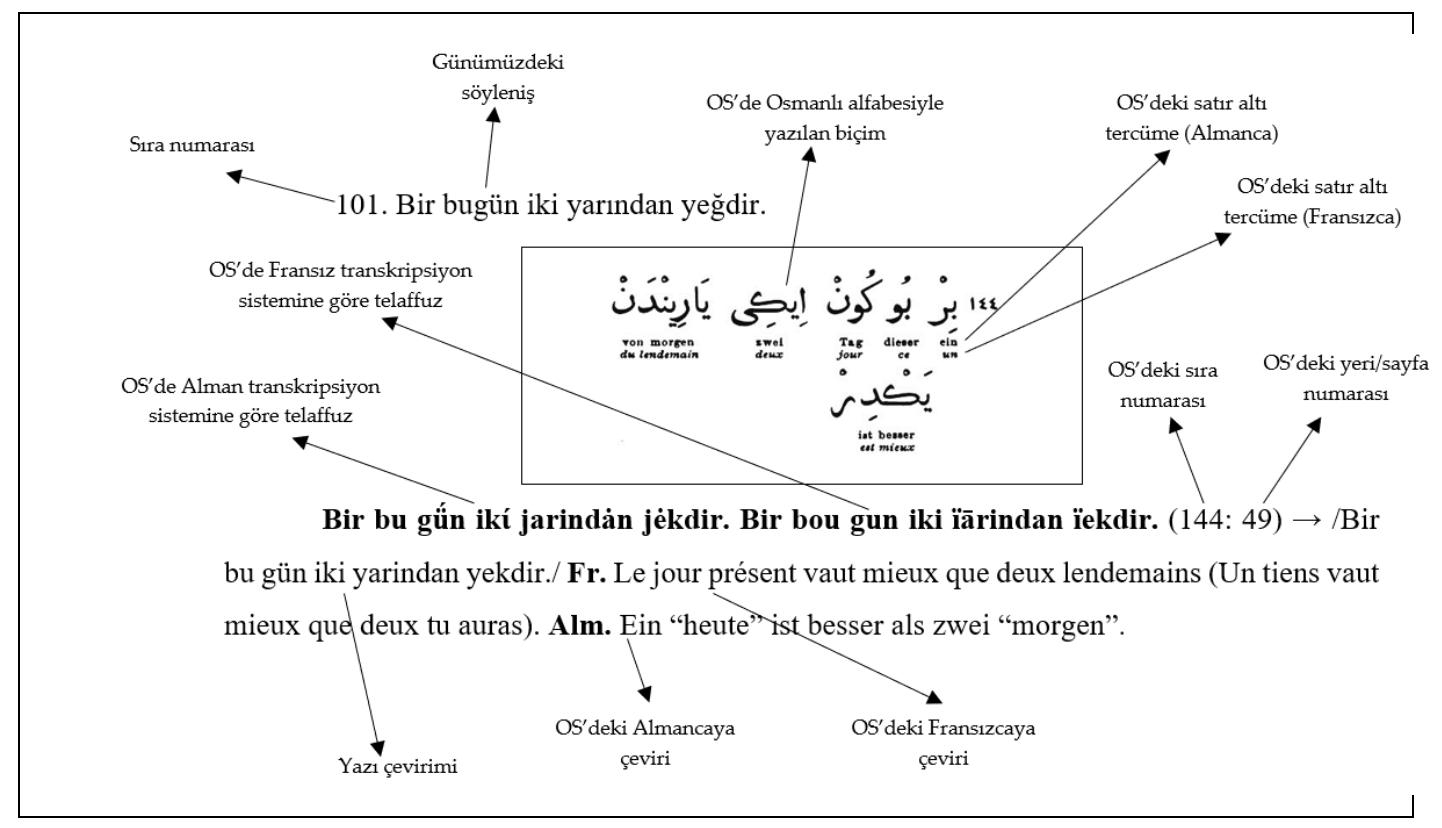

101. Bir bugün iki yarından yeğdir.

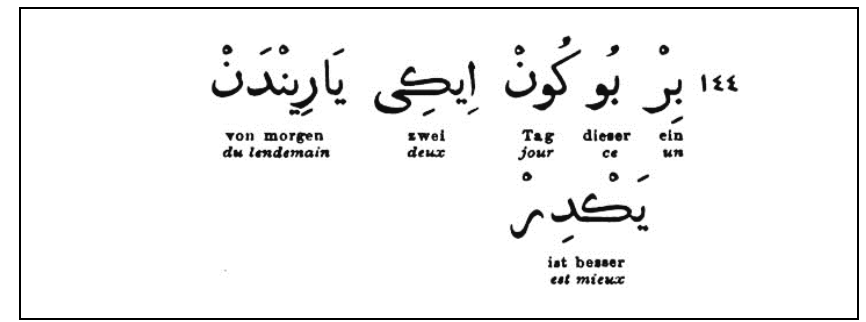

Bir bu gû́n ikí jarindản jèkdir. Bir bou gun iki ïārindan ïekdir. (144: 49) $\rightarrow$ /Bir bu gün iki yarindan yekdir./ Fr. Le jour présent vaut mieux que deux lendemains (Un tiens vaut mieux que deux tu auras). Alm. Ein "heute" ist besser als zwei "morgen".

102. Bir çıplak bin cebelü soymaz.

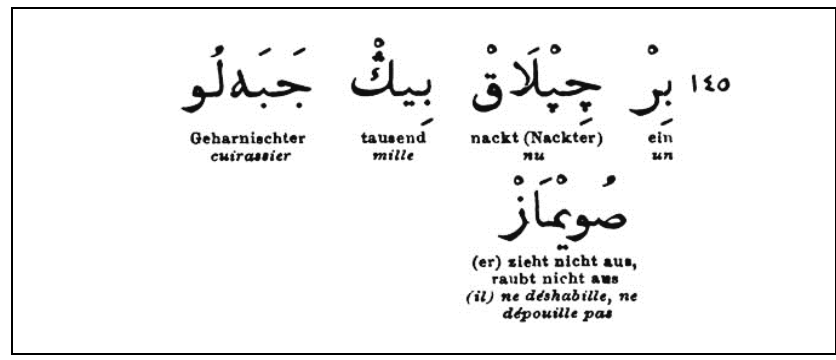

Bir tschiplảk bin dschebelú ßoimảf. Bir tchiplāq bîñ djebelu soïmāz. (145: 49) $\rightarrow$ /Bir çiplak bin biñ cebelü soymaz./ Fr. Mille cuirassiers ne sauraient dépouiller un homme nu. Alm. Tausend Geharnischte ziehen Einen Nackten nicht aus. 
103. Bir çiçek ile yaz olmaz.

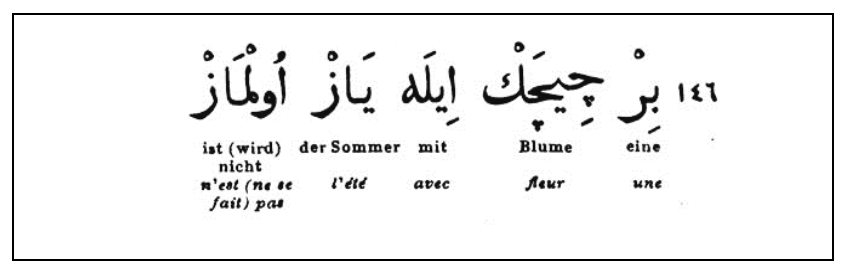

Bir tschitschèk ilè jaf olmàf. Bir tchîtchek ilè iaāz olmāz. (146: 49) $\rightarrow$ /Bir çiçek ile yaz olmaz./ Fr. Une fleur ne fait pas l'été (Une hirondelle ne fait pas le printemps). Alm. Eine Blume macht keinen Sommer (Eine Schwalbe macht keinen Sommer).

104. Bir evde horoz çok olunca sabah geç olur.

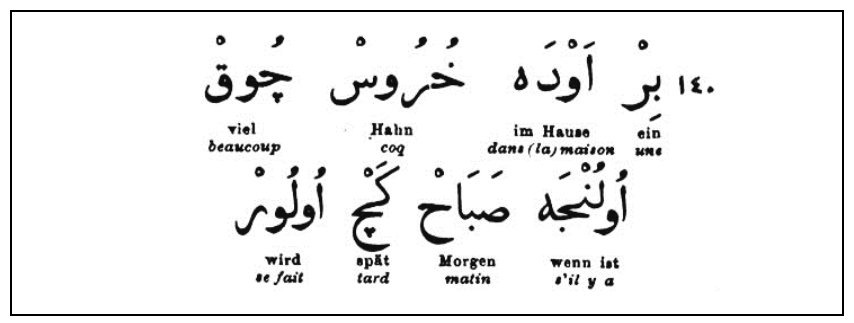

Bir ewdè choròs tschok olúndscha ßabảh gètsch olúr. Bir evdè khoros tchoq oloundja sabāh guetch olour. (140: 47) $\rightarrow$ /Bir evde ḩoros çok olunca sabah geç olur./ Fr. Le jour se lève tard dans une maison où les coqs sont nombreux. Alm. Im Hause wo viele Hähne sind, wird es spät Morgen (Viele Köche versalzen die Suppe).

105. Biri eker, biri biçer.

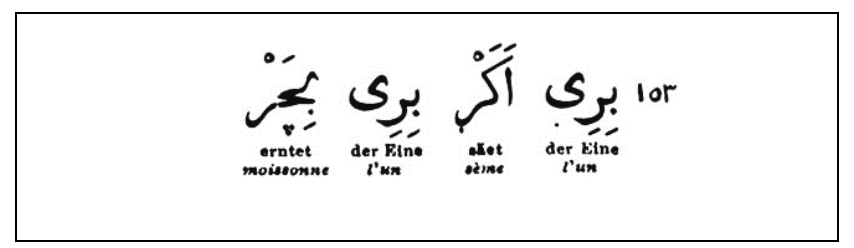

Birí ekèr birí bitschèr. Biri èker biri bitcher. (153: 53) $\rightarrow$ /Biri eker biri biçer./ Fr. L'un sème, l'autre moissone. Alm. Der Eine säet, der Andere erntet.

106. Bir iyi şarap ve bir dilber avrat iki tatlı zehirdir.

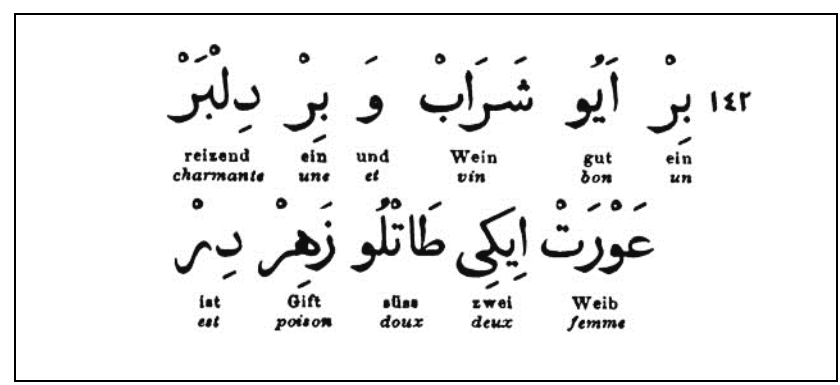

Bir ejû́ scheràb we bir dilbèr awrèt ikí thatlú fehír dir. Bir eïu cherāb vè bir dilber 'avret iki thātlu zehir dir. (142: 49) $\rightarrow$ /Bir eyü şerab ve bir dilber avret 'avret iki tatlü zehirdir./ Fr. Bon vin et jolie femme sont deux poisons bien doux. Alm. Guter Wein und ein reizendes Weib sind zwei süsse Gifte. 
107. Bir kanat ile kuş uçmaz.

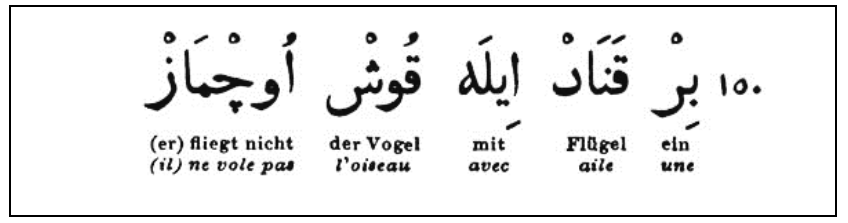

Bir kanảd ilè kusch utschmảf. Bir qanād ilè qouch outchmāz. (150: 51) $\rightarrow$ /Bir kanad ile kuş uçmaz./ Fr. L'oiseau ne saurait voler d'une aile. Alm. Mit Einem Flügel kann der Vogel nicht fliegen.

108. Bir kişide iki hüner olmaz.

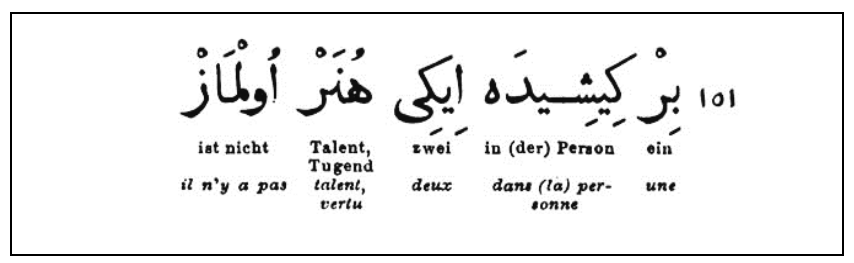

Bir kischidè ikí hünèr olmảf. Bir kichidè iki huner olmāz. (151: 51) $\rightarrow$ /Bir kişide iki hüner olmaz./ Fr. Nul homme ne possède deux perfections. Alm. Niemand besitzt zwei Vollkommenheiten.

109. Bir mih bir nalı, bir nal bir atı, bir at bir eri, bir er bir memleketi kurtarır.

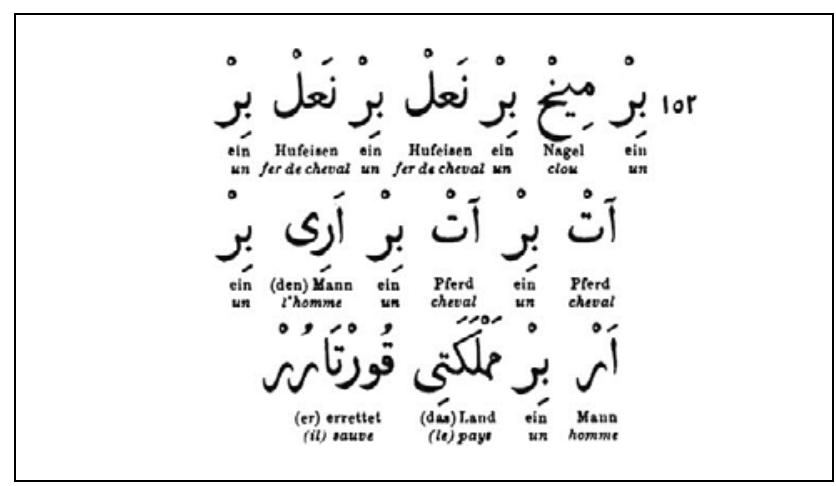

Bir mích bir nảl bir nảl bir àt bir àt bir erí bir èr bir memleketí kurtarúr. Bir mîkh bir na'l bir na'l bir ât bir ât bir eri bir er bir memleketi qourtārur. (152: 51) $\rightarrow$ /Bir mih bir nal na' 1 bir nal na' 1 bir at bir at bir eri bir er bir memleketi kurtarür./ Fr. Le clou soutient le fer du cheval, le fer soutient le cheval, le cheval soutient l'homme, l'homme soutient le pays. Alm. Der Nagel beschützt das Hufeisen, das Hufeisen das Pferd, das Pferd den Mann, der Mann das Land.

110. Bir ok iki kuş almaz.

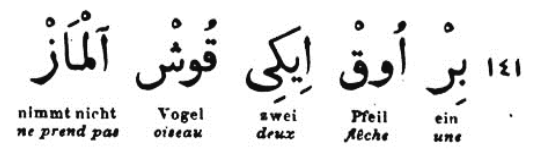

Bír ok ikí kusch almȧf. Bir oq iki qouch âlmāz. (141: 47) $\rightarrow$ /Bir ok iki kuş almaz./ Fr. D'un seul coup de flêche on n'attrape pas deux oiseaux. Alm. Ein Pfeil trifft nicht zwei Vögel 
(zugleich).

111. Bir söyle, iki fikreyle.

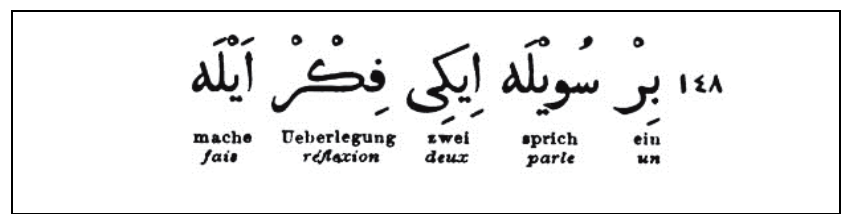

Bir söjlè ikí fikr ejlè. Bir seuilè iki fikr eïlè. (148: 51) $\rightarrow$ /Bir söyle iki fikreyle./ Fr. Réfléchis deux fois avant de parler une fois. Alm. Sprich Ein Mal, überlege zwei Mal.

112. Bir sürçen atın budunu vurmazlar.

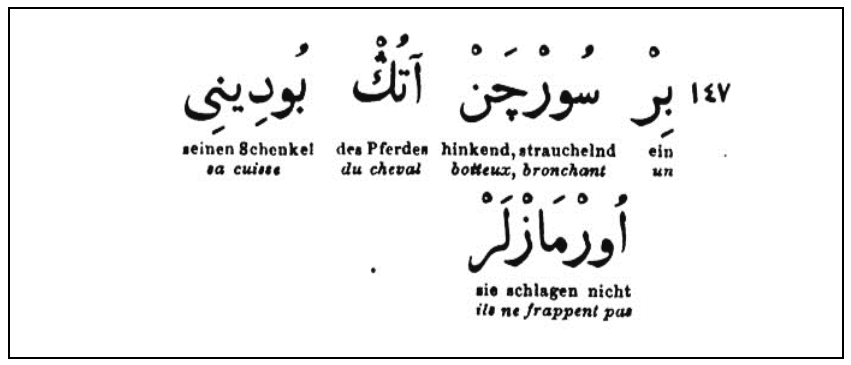

Bir sürtschèn atẏn budunú wurmaflảr. Bir surtchen âtyñ boudounou vourmāzlar. (147: $51) \rightarrow$ /Bir sürçen atın atın budunu vurmazlar./ Fr. Cheval qui boite ne se frappe pas sur la jambe. Alm. Ein Pferd, das hinkt, schlägt man nicht auf's Bein.

113. Bir taş ile dokuz koz vurulmaz.

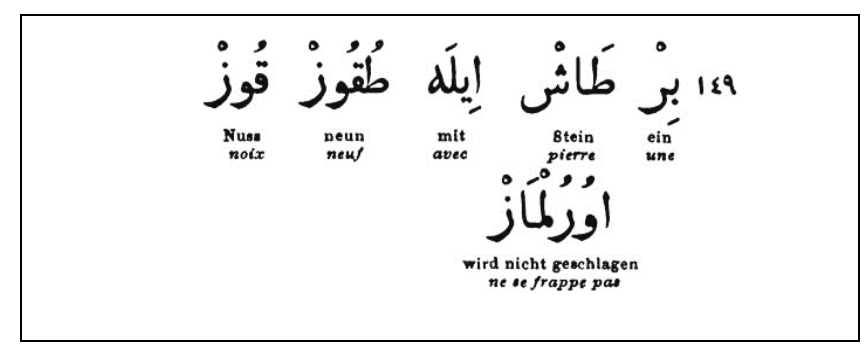

Bir thasch ilè dhokúf kof wurulmảf. Bir thāch ilè dhoqouz qoz vouroulmāz. (149: 51) $\rightarrow$ /Bir taş ile dokuz koz vurulmaz./ Fr. D'un seul coup de pierre on ne casse pas neuf noix. Alm. Neun Nüsse öffnet man nicht mit Einem Schlage.

114. Bir vurmak ile ağaç düşmez.

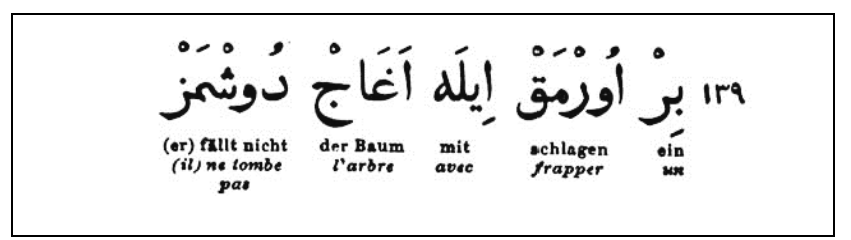

Bir wurmảk ilè aghảdsch düschmèf. Bir vourmaq ilè aghādj duchmez. (139: 47) $\rightarrow$ /Bir vurmak ile ağac düşmez./ Fr. L'arbre ne tombe pas d'un seul coup (Paris n'a pas été bâti en un jour). Alm. Auf einen Hieb fällt kein Baum. 
115. Borçlunun benzi sararır.

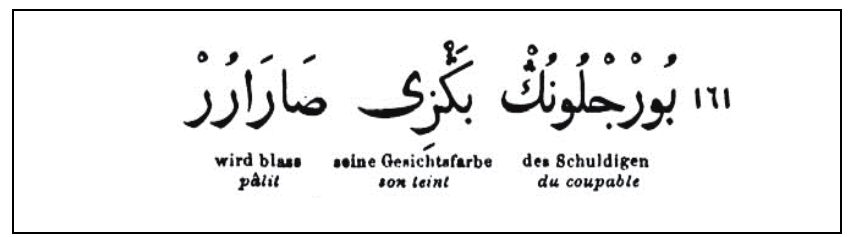

Bordschlunỷn benfí Bararür. Bordjlounyñ beñzi sārārur. (161: 55) $\rightarrow$ /Borclunın borclunıñ benzi beñzi sararür./ Fr. Le coupable pâlit. Alm. Das Antlitz des Schuldigen erbleicht.

116. Borçsuz yoksul beyden yeğdir.

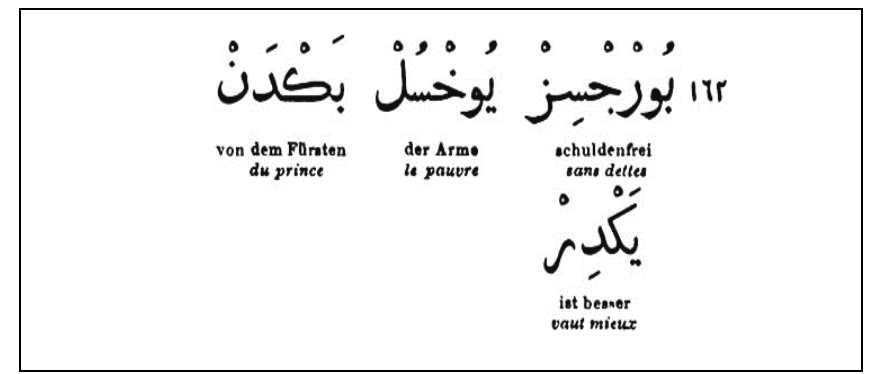

Bordschsẏf jochsúl bejdèn jèkdir. Bordjsyz ïokhsoul beïden ïekdir. (162: 55) $\rightarrow$ /Borcsiz yohsul beyden yekdir./ Fr. Pauvre sans dettes vaut mieux que prince. Alm. Besser arm und schuldenfrei, als ein Fürst sein.

117. Boş çuval durmaz.

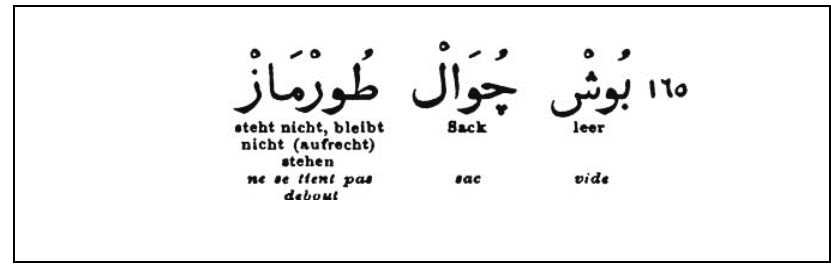

Bosch tschüwảl dhurmȧf. Bôch tchuvāl dhourmāz. (165: 57) $\rightarrow$ /Boş çüval durmaz./ Fr. Sac vide ne reste pas debeout. Alm. Ein leerer Sack bleibt nicht aufrecht stehen.

118. Boş torba ile at tutulmaz.

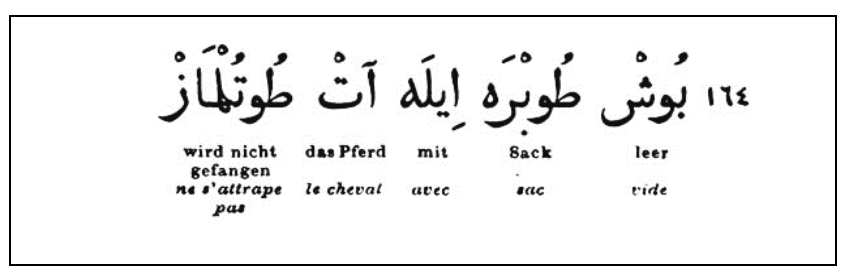

Bỏsch thorbả ilè àt thutulmảf. Boch thorba ilè ât thoutoulmāz. (164: 55) $\rightarrow$ /Boş torba ile at tutulmaz./ Fr. Sac vide n'attire pas cheval. Alm. Mit einem leeren Sacke lockt man kein Pferd in den Stall. 
119. Bugün bana ise yarın sanadır.

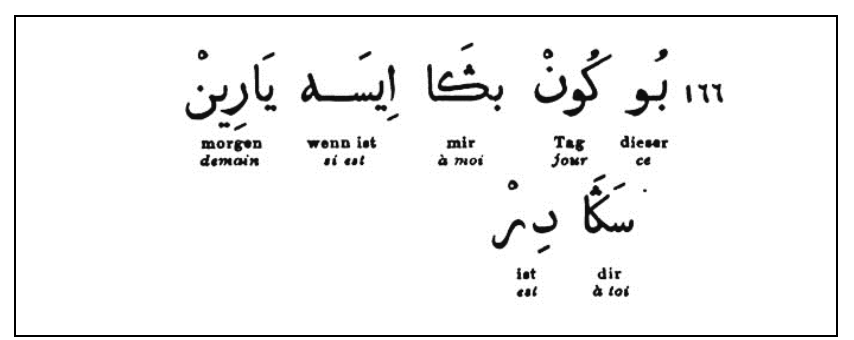

Bu gün banả isė jarín sanả dír. Bou gun bañā isè iāāin sañā dir. (166: 57) $\rightarrow$ /Bugün bana baña ise yarin sanadir sañadir./ Fr. Chacun a son tour. Alm. Heute mir, morgen dir.

120. Bugünkü tavuk yarınki kazdan yeğdir.

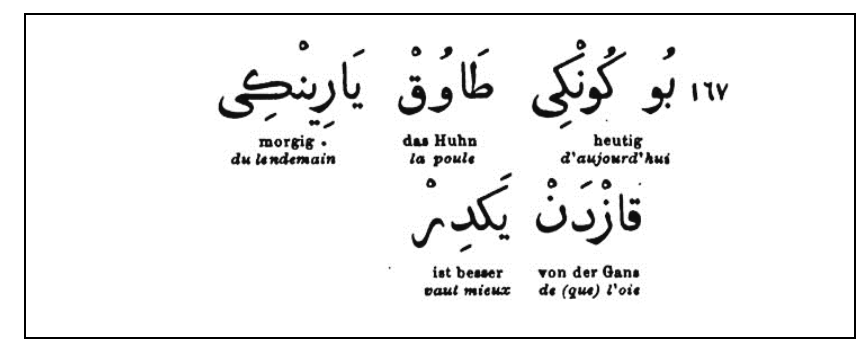

Bu günkí thaúk jarinkí kafdản jèkdir. Bou gunki thāouq ïārinki qāzdan ïekdir. (167: 57) $\rightarrow$ /Bugünki tauk yarinki kazdan yekdir./ Fr. La poule d'aujourd'hui vaut mieux que l'oie de demain (Mieux vaut un tiens que deux tu auras). Alm. Besser heute ein Huhn als morgen eine Gans (Ein Sperling in der Hand ist besser als eine Taube auf dem Dache).

121. Bugünkü yumurta yarınki tavuktan yeğdir.

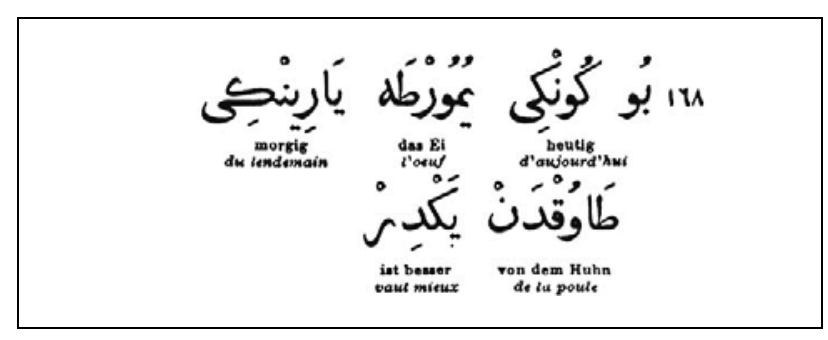

Bu günkí jumurthả jarinkí thaúkdản jèkdir. Bou gunki ïoumourtha īārinki thāouqdan iekdir. (168: 57) $\rightarrow$ /Bugünki yumurta yarinki taukdan yekdir./ Fr. L'oeuf d'aujourd'hui vaut mieux que la poule du lendemain. Alm. Besser heute ein Ei als morgen ein Huhn.

122. Burun yüzden düşmez.

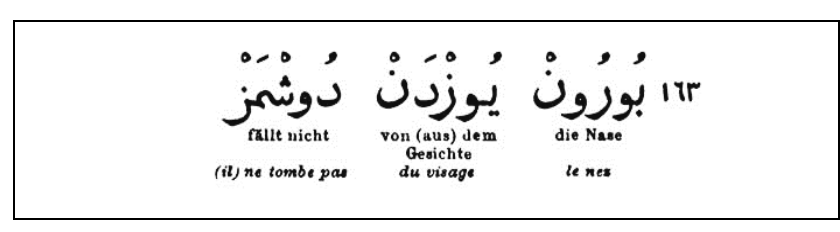

Burún jüfdèn düschmèf. Bouroun ïuzden duchmez. (163: 55) $\rightarrow$ /Burun yüzden düşmez./ Fr. Le nez ne tombe pas du visage. Alm. Die Nase fällt nicht aus dem Gesichte. 
123. Büyük başın büyük ağrısı var.

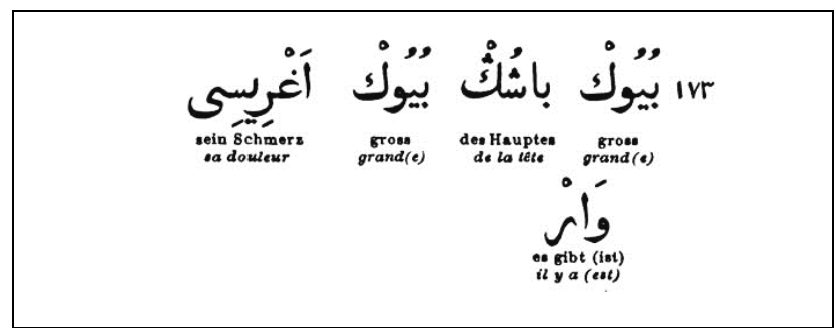

Büjúk baschỷn büjúkk aghrisí wảr. Buïuk bāchyñ buïuk aghriçi vār. (173: 59) $\rightarrow$ /Büyük başın başıñ büyük ağrisi var./ Fr. Grandeurs amènent soucis. Alm. Grosser Kopf, grosse Sorgen.

124. Büyük bıçak belinde getirmekle aşçı değil.

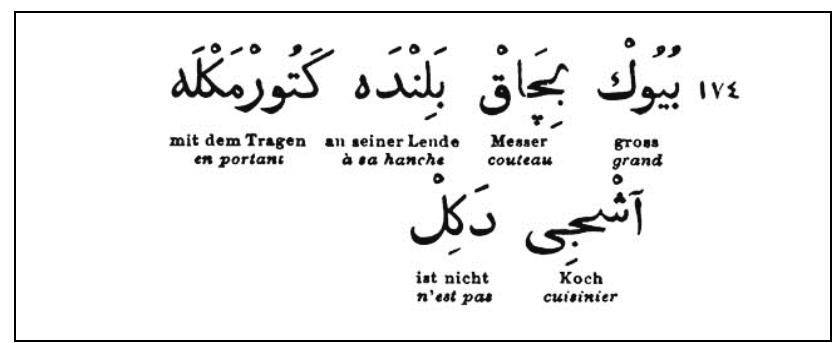

Büjúk bytschảk belindè getürmėgle aschdschí dejíl. Buïuk bytchāq belindè gueturmeglè âchdji deïil. (174: 59) $\rightarrow$ /Büyük bıçak belinde getürmeğle aşci deyil./ Fr. Le coutelas ne fait pas le cuisinier. Alm. Das Küchenmesser macht noch nicht den Koch.

125. Cahil olan daima şad olayım der elem çeker.

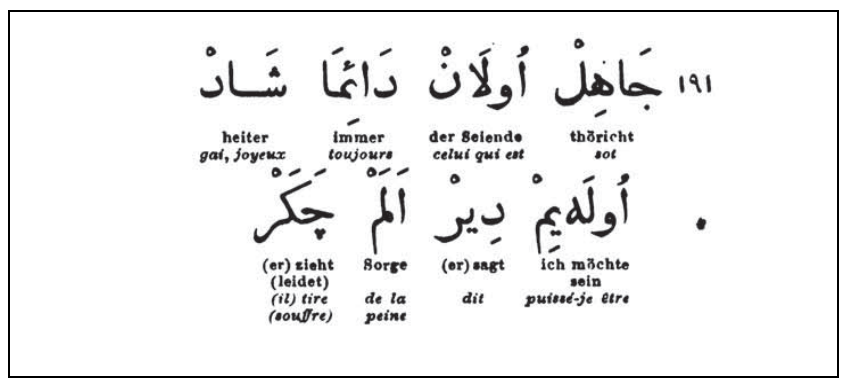

Dschahíl olản dảima schảd oläïm der elèm tschekèr. Djāhil olān dāïmā chād olaïm der elem tcheker. (191: 65) $\rightarrow$ /Cahil olan dayma şad olaym der elem çeker./ Fr. Le chagrin du sot est de vouloir toujours être gai. Alm. Der Kummer des Thoren ist, immer froh sein zu wollen.

126. Cahil olan kimse vakitsiz horoz gibidir.

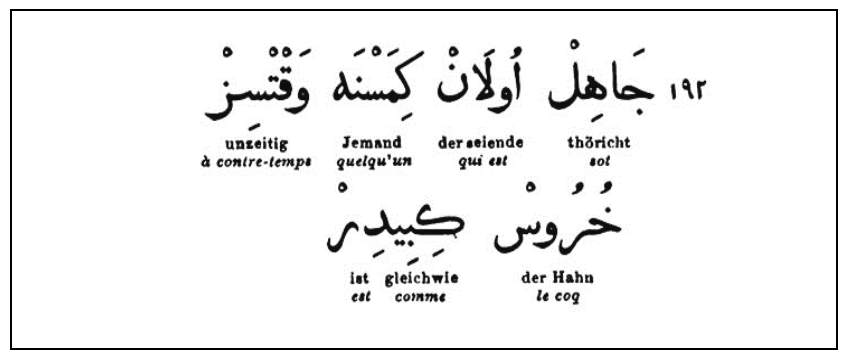


Dschahíl olản kimesnè wakytsỳf (waktsỳf) ${ }^{2}$ choròs gibídir. Djāhil olān kimesnè vaqytsyz (vaqtsyz) khoros guibidir. (192: 65) $\rightarrow$ /Cahil olan kimesne vakıtsız (vaktsız) horos gibidir./ Fr. Le sot ressemble à un coq qui chante à contre temps. Alm. Der Thor gleicht einem Hahn, der zur Unzeit kräht.

127. Can canın yoldaşıdır.

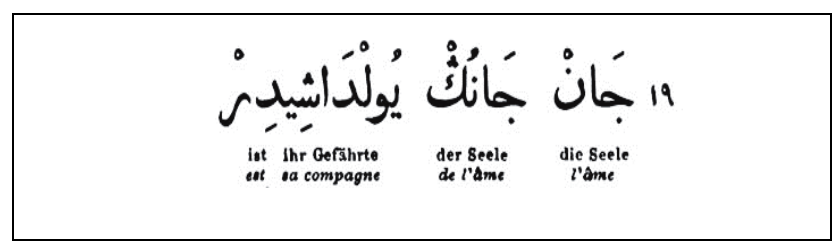

Dschan dschanỷn joldaschídir. Djān djānyñ ïoldāchidir. (190: 65) $\rightarrow$ /Can canın canıñ yoldaşidir./ Fr. Les âmes voyagent de compagnie. Alm. Seele und Seele sind Weggenossen.

128. Ceht ve sabır ile sıçan tahtayı deler.

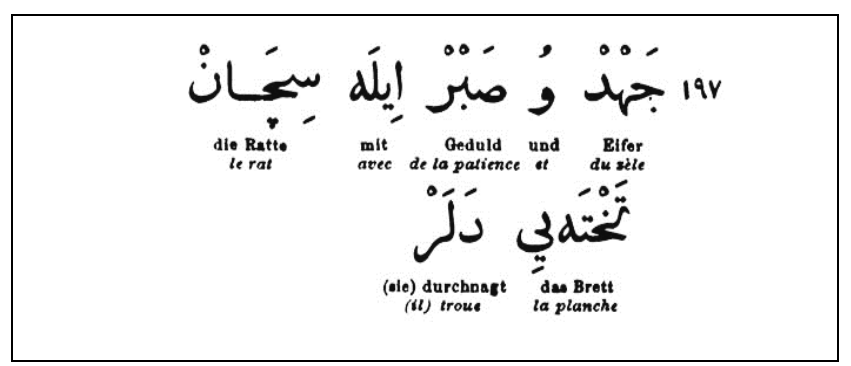

Dschehd u ßảbr ilè sitschản tachtají delèr. Djehd ou sabr ilè sitchān takhtaïi deler. (197: 67) $\rightarrow$ /Cehd u sabr ile siçan tahtayi deler./ Fr. Avec du zèle et de la patience la souris perce une planche. Alm. Mit Eifer und Bestand durchnagt die Maus die Bretterwand.

129. Cemaat ne kadar çok olsa imam bildiğini okur.

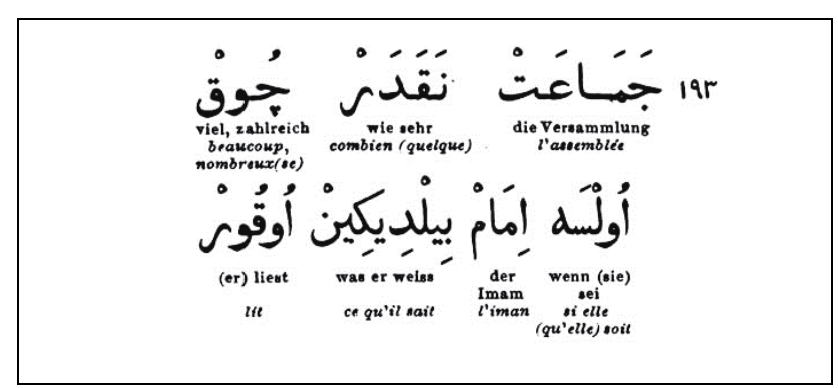

Dschemaảt nėkadảr tschok olsả imảm bildigín okúr. Djemā’at neqadar tchoq olsa imām bildiguin oqour. (193: 65 ) $\rightarrow$ /Cemaat $\sim$ cema'at ne kadar çok olsa imam bildiğin okur./ Fr. Quelque nombreuse que soit l'assemblée, le prédicateur ne récite que ce qu'il sait. Alm. Wie gross auch die Versammlung sei, der Prediger predigt nur was er weiss.

Parantez içindeki biçimler OS’de “yerine, ya da" olarak gösterilen telaffuz şeklidir. 
130. Cihanda yâr ol, bâr olma.

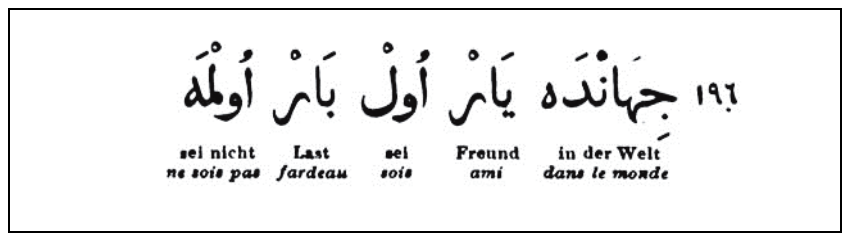

Dschyhandả jảr ol bar òlma. Djyhānda ïār ol bār olma. (196: 67) $\rightarrow$ /Cihanda yar ol bar olma./ Fr. Soyez aimable, mais sans devenir insupportable. Alm. Sei ein Freund auf der Erde und nicht eine Beschwerde.

131. Cimrinin oğlu inatçı olur.

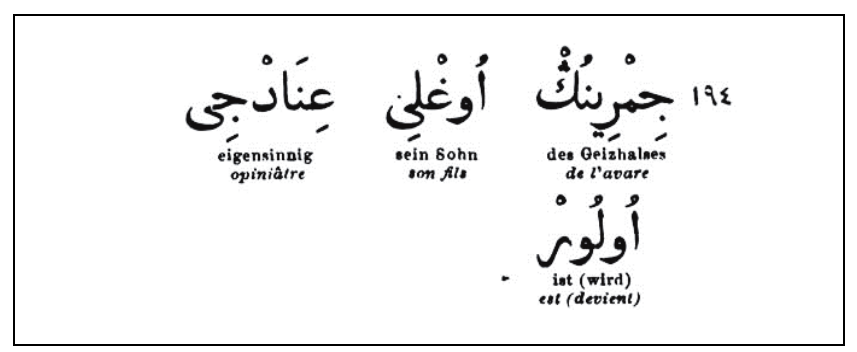

Dschimrinẏn oghlú ínaddschí olúr. Djimrînyñ oghlou 'inaddji olour. (194: 65) $\rightarrow$ /Cimrinın cimrinıñ oğlu inadci 'inadci olur./ Fr. Le fils de l'avare devient opiniâtre. Alm. Der Sohn des Geizhalses wird ein Trotzkopf.

132. Çağrilmayan yerde kedi ile köpek var.

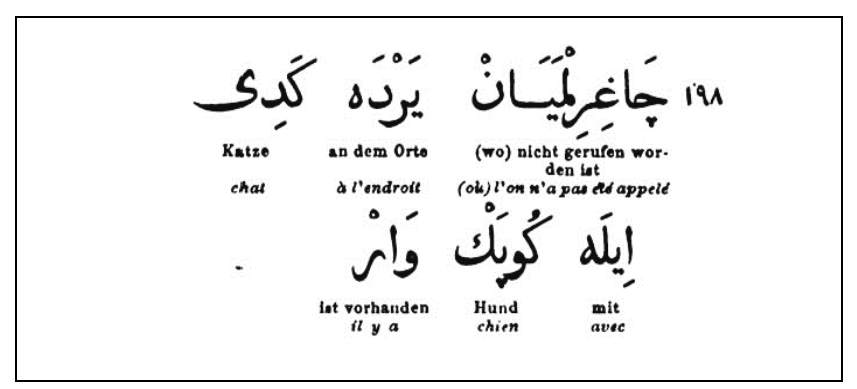

Tschaghyrílmajản jerdè kedí ilè kjöpèk war. Tchāghyrilmaïān ïerdè kedi ilè kieupek vār. (198: 67) $\rightarrow$ /Çağırilmayan yerde kedi ile köpek var./ Fr. Chiens et chats sont partout où on ne les appelle pas. Alm. Hund und Katze sind überall, wo man sie nicht ruft.

133. Çatal kazık yere girmez.

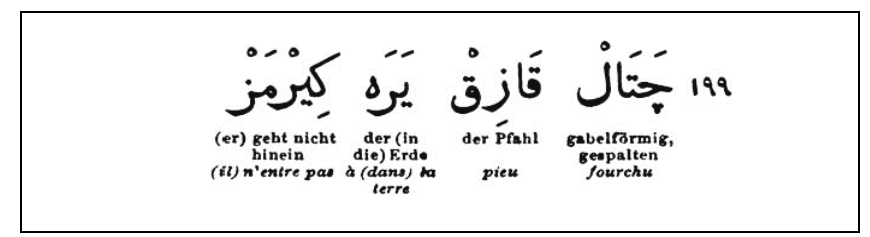

Tschatảl kafỷk jeré girmèf. Tchatāl qāzyq ïerè guîrmez. (199: 67) $\rightarrow$ /Çatal kazık yere girmez./ Fr. Pieu fendu n'entre pas dans la terre. Alm. Gespaltene Pfähle lassen sich nicht einschlagen. 
134. Çivisiz pedavrayı yel alır.

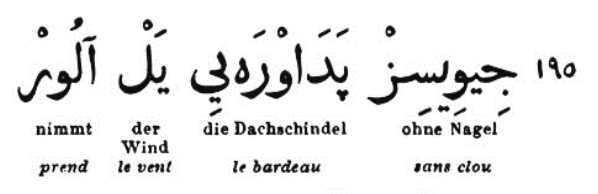

Dschiwisẏ1 padawrají jel alúr. Djivîsyz padāvraïi iel âlur. (195: 65) $\rightarrow$ /Civisız padavrayi yel alur./ Fr. Lorsque bardeau n'est pas cloué, le vent l'emporte. Alm. Die ungenagelte Dachschindel entführt der Wind.

135. Çobanın armağanı çam sakızıdır.

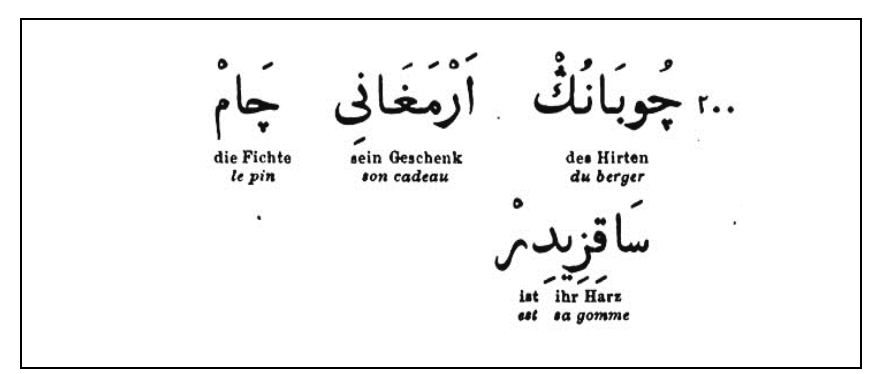

Tschobanỷn ermaghaní tscham sakifídir. Tchobānyñ ermaghāní tchām sāqizidir. (200: $67) \rightarrow$ /Çobanın çobanıñ ermağani çam sakizidir./ Fr. Le berger donne en cadeau de la résine (Chacun selon ses moyens). Alm. Des Hirten Geschenk ist Fichtenharz (Arme Leute kochen mit Wasser).

136. Çok arpa atı çatlatır.

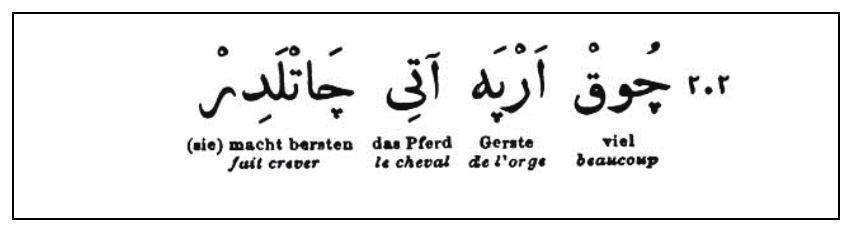

Tschỏk arpả atí tschatladír. Tchoq arpa âti tchātladir. (202: 69) $\rightarrow$ /Çok arpa ati çatladir./ Fr. Trop d'orge fait crever le cheval. Alm. Zu viel Gerste macht das Pferd bersten.

137. Çok bilen çok yanılır.

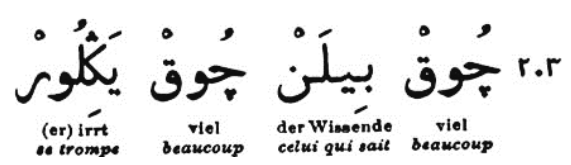

Tschỏk bilèn tschök janylür. Tchoq bilen tchoq ïañylur. (203. 69) $\rightarrow$ /Çok bilen çok yanılür yañılür./ Fr. Grand savant se trompe souvent. Alm. Wer viel weiss, fehlt viel. 
138. Çok karınca arslanı öldürür.

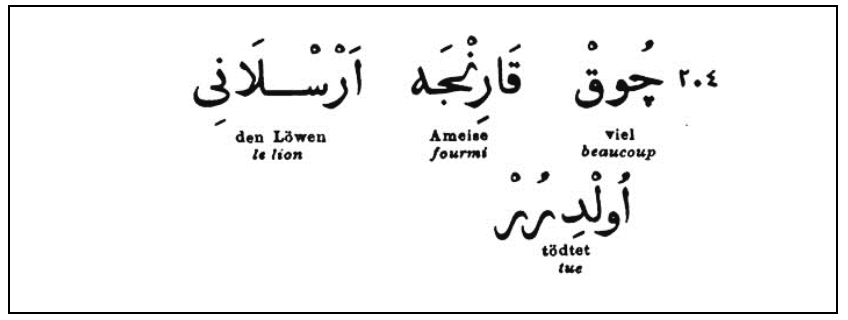

Tschỏk karindschả arslaní öldürǘr. Tchoq qārindja arslāni euldurur. (204: 69) $\rightarrow$ /Çok karinca arslani öldürür./ Fr. Beaucoup de fourmis tuent le lion. Alm. Wiele Ameisen tödten den Löwen (Viele Hunde sind des Hasen Tod).

139. Çok kelam söyleyen insanın kalbi sağ olmaz.

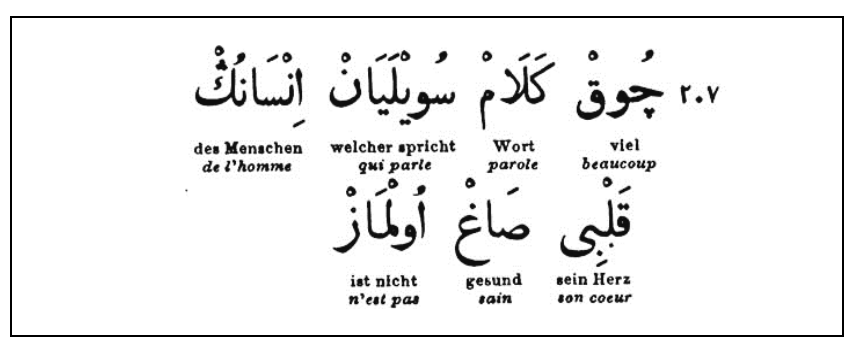

Tschỏk kelàm söjlejèn insanẏn kalbí ßảgh olmảf. Tchoq kelām seuileïen insānyñ qalbi sāgh olmāz. (207: 69) $\rightarrow$ /Çok kelam söyleyen insanın insanıñ kalbi sağ olmaz./ Fr. Beaucoup de paroles, mauvaise conscience. Alm. Viele Worte, schlechtes Gewissen.

140. Çok koyunun çok kuzusu olur.

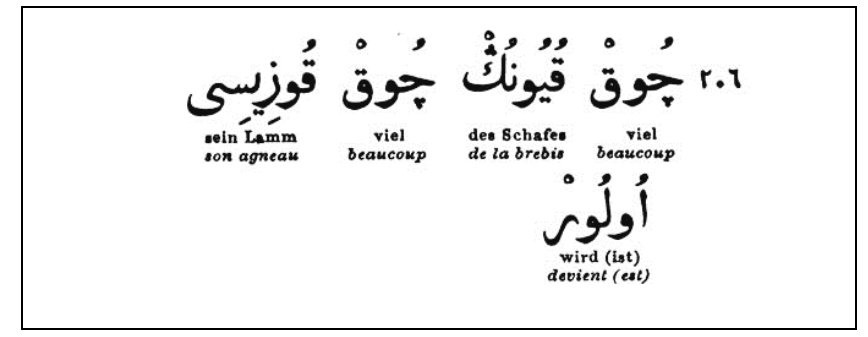

Tschỏk kojunún tschok kufusú olúr. Tchoq qoïounouñ tchoq qouzouçou olour. (206: 69) $\rightarrow$ /Çok koyunun koyunuñ çok kuzusu olur./ Fr. Beaucoup de brebis, beaucoup d'agneaux. Alm. Viele Schafe, viele Lämmer.

141. Çok kucaklayan az devşirir.

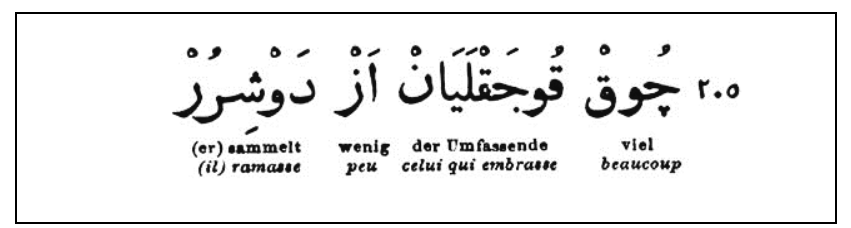

Tschỏk kodschaklajản af dewschirúr. Tchoq qodjaqlaïān az devchirur. (205: 69) $\rightarrow$ /Çok kocaklayan az devşirür./ Fr. Qui trop embrasse mal étreint. Alm. Wer zu viel umfasst, heimst wenig ein. 
142. Çok naz âşı̆̆ı usandırır.

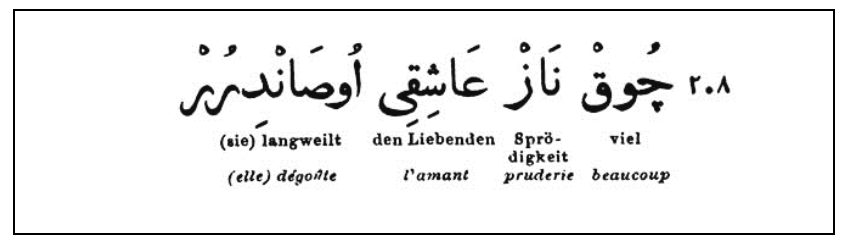

Tschỏk nảf aschikí ußandirúr. Tchoq nāz 'āchiqi ouçāndirur. (208: 69) $\rightarrow$ /Çok naz aşiki 'âşiki usandirür./ Fr. Trop de pruderie dégoûte l'amant. Alm. Zu viel Sprödigkeit ermüdet den Liebenden.

143. Çok yaşayan çok bilmez, çok gezen çok bilir.

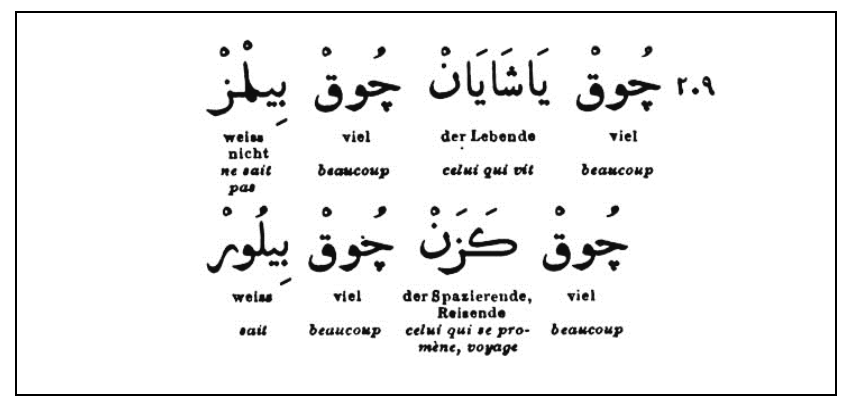

Tschỏk jaschäjản tschỏk bilmèf tschỏk gefèn tschỏk bilúr. Tchoq ïāchāiān tchoq bilmez tchoq guezen tchoq bilur. (209: 71) $\rightarrow$ /Çok yaşayan çok bilmez çok gezen çok bilür./ Fr. Ce n'est pas en vivant longtemps, mais en voyageant beaucoup, qu'on acquiert de l'expérience. Alm. Nicht langes Leben macht klug, aber langes Reisen.

144. Çürük baklanın kör alıcısı olur.

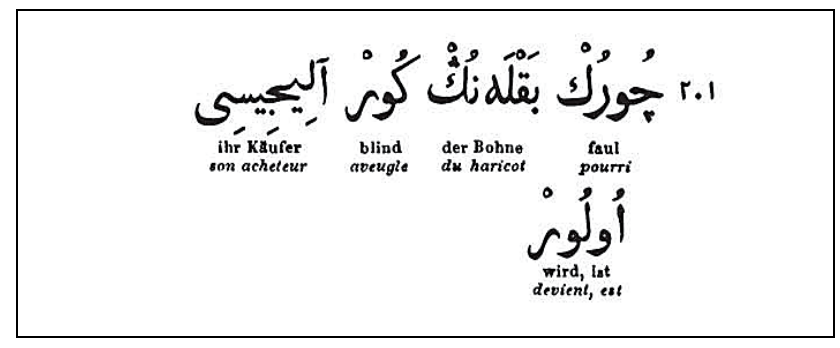

Tschürúk baklanẏn kjör alidschisí olúr. Tchuruk baqlanyñ kieur âlidjiçi olour. (201: 67) $\rightarrow$ /Çürük baklanın baklanıñ kör alicisi olur./ Fr. A haricots pourris acheteur aveugle. Alm. Faule Bohnen finden einen blinden Käufer.

145. Dağ başından duman, yiğit başından güman eksik değil.

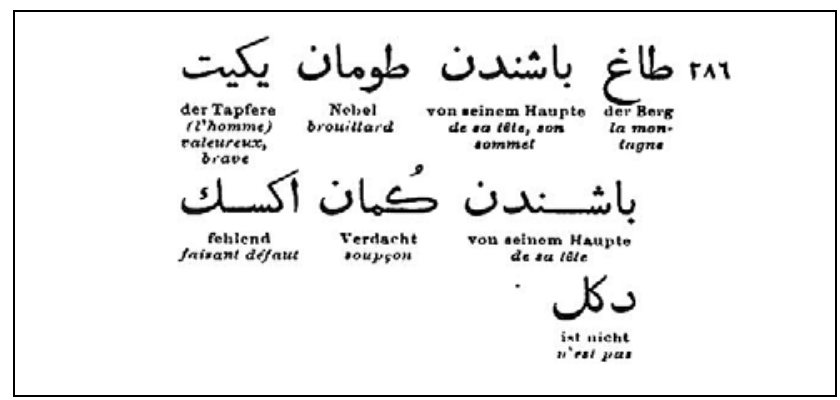

Dhagh baschindản dhumản jijít baschindản gümản eksík dejíl. Dhāgh bāchindan 
dhoumān iiiiit bāchindan gumān eksik deïil. (286: 93) $\rightarrow$ /Dağ başindan duman, yiyit başindan güman eksik deyil./ Fr. Pas de montagne sans vapeurs, ni d'homme de mérite sans détracteurs. Alm. Kein Berggipfel ohne Nebeldunst, keine Menschengrösse ohne Missgunst.

146. Dağ dağa ulaşmaz, insan insana ulaşır.

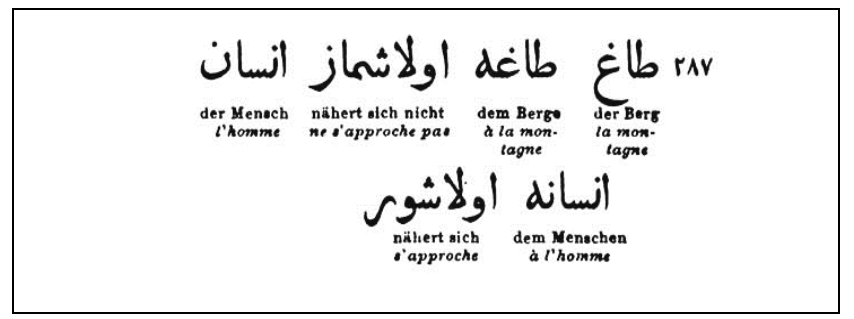

Dhảgh dhaghả ulaschmảf insản insanả ulaschúr. Dhāgh dhāgha oulāchmaz insān insāna oulāchur. (287: 95) $\rightarrow$ /Dağ dağa ulaşmaz insan insana ulaşür./ Fr. Les montagnes ne se rencontrent pas, mais les hommes se rencontrent. Alm. Berge begegnen sich nicht, aber Menschen sehen sich wieder.

147. Damlaya damlaya göl olur, düşman gözü kör olur.

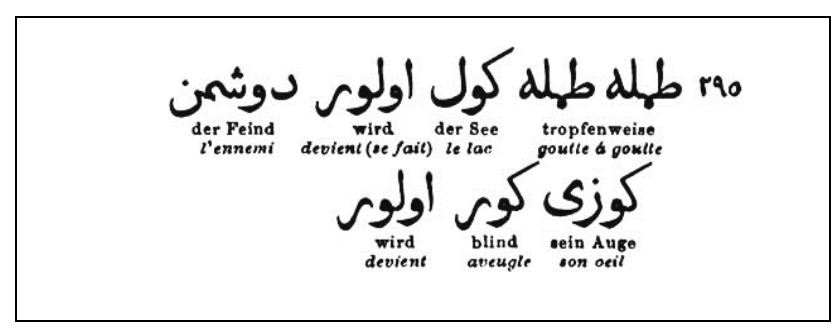

Dhamlả dhamlả göl olúr düschmėn göfi kjör olúr. Dhamla dhamla gueul olour duchmen gueuzi kieur olour. (295: 97) $\rightarrow$ /Damla damla göl olur düşmen gözi kör olur./ Fr. Goutte à goutte le lac se remplit; peu à peu l'oeil de l'ennemi s'affaiblit. Alm. Tropfen werden zum See; auch das Auge des Feindes wird mit der Zeit blind.

148. Danışan dağ aşmış, danışmayan yolda kalmış.

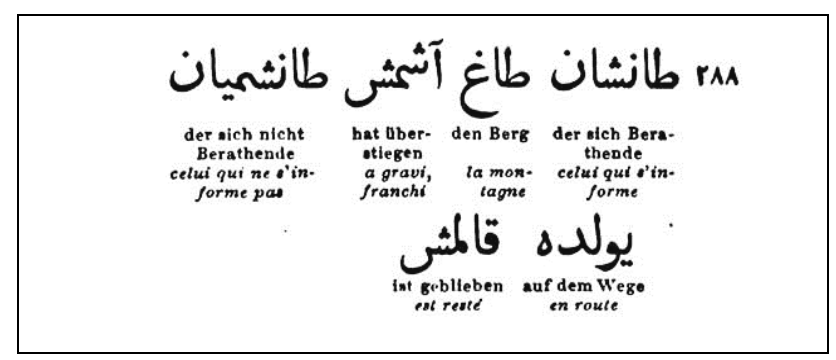

Dhanyschản dhagh aschmẏsch danẏschmajản joldả kalmỷsch. Dhānychān dhāgh âchmych dhānychmaīān ïolda qālmych. (288: 95) $\rightarrow$ /Danışan dağ aşmış, danışmayan yolda kalmış./ Fr. Qui prend conseil franchit l'espace, et qui n'en prend pas reste sur place. Alm. Wer anfrug hat den Berg überstiegen, wer nicht anfrug, blieb anf dem Wege liegen. 
149. Darılmış kudurmuştan beterdir.

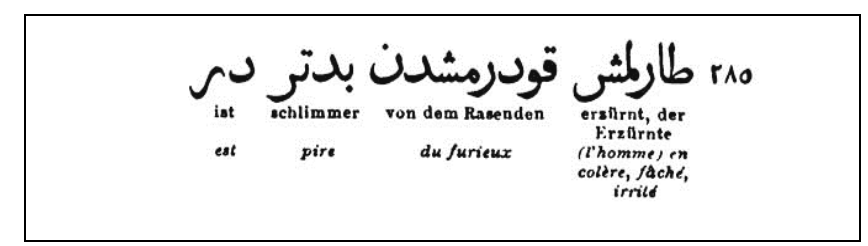

Dharylmẏsch kudurmuschdản bedtėr dir. Dhārylmych qoudourmouchdan bedter dir. (285: 93) $\rightarrow$ /Darılmış kudurmuşdan bedterdir./ Fr. Colère est pire que rage. Alm. Der Zornige ist schlimmer als der Rasende.

150. Davacın kadı olunca yardımcın Allah ola.

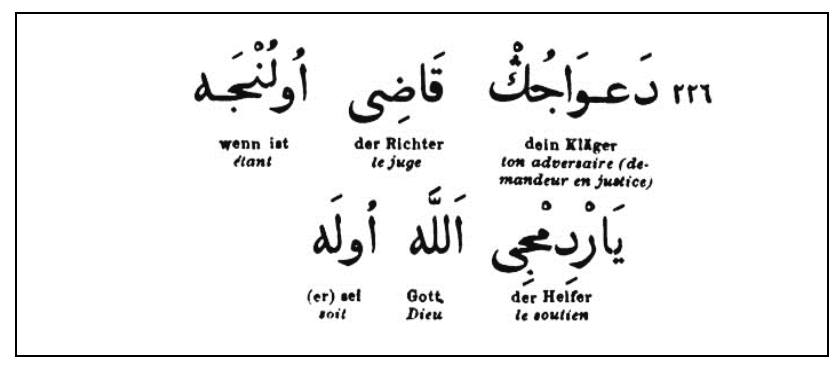

Dawadschỷn kafí olúndscha jardymdschí allàh olả. Da'vādjyñ qāzi oloundja ïārdymdji allah ola. (226: 77) $\rightarrow$ /Davacın davacıñ kazi olunca yardımci Allah ola./ Fr. Si contre toi le juge plaide, Dieu te soit en aide! Alm. Ist der Richter dein Kläger, dann sei Gott dein Helfer!

151. Davul ile gelen zurna ile gider.

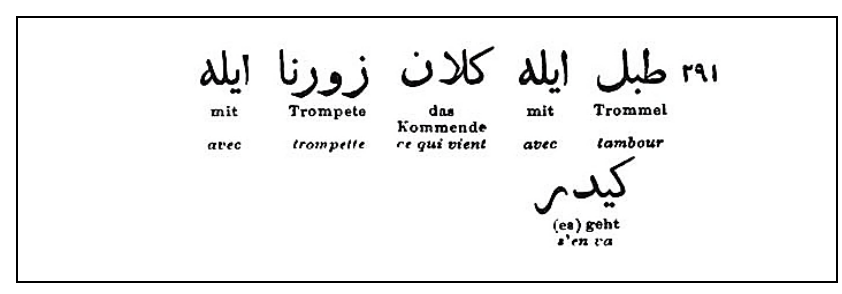

Thaúl (thabl) ilè gelèn furnả ilè gidèr. Thaoul (thabl) ilè guelen zournā ilè guider. (291: 95) $\rightarrow$ /Taul (tabl) ile gelen zurna ile gider./ Fr. Ce qui vient par le tambour s'en va par la trompette (Ce qui vient par la flûte s'en va par le tambour). Alm. Was man durch die Trommel gewinnt, verliert man durch die Trompete (Wie gewonnen, so zerronnen).

152. Davul sedası uzakdan hoş gelir.

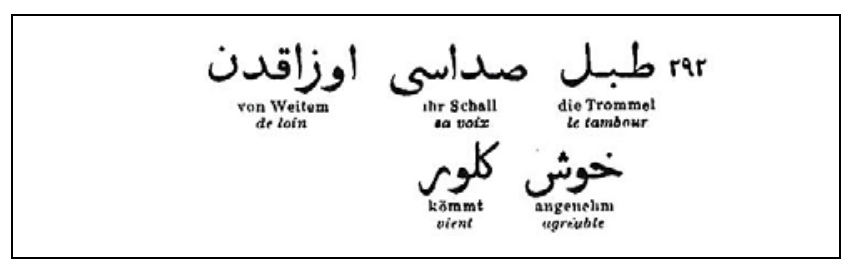

Thaúl Bedasí ufakdản chỏsch gelúr. Thaoul sedāçi ouzāqdan khoch guelur. (292: 95) $\rightarrow$ /Taul sedasi uzakdan hoş gelür./ Fr. De loin le son du tambour paraît agréable. Alm. Trommelschall klingt angenehm aus der Ferne. 
153. Dayinlerin borçlularından iyi fikri vardır.

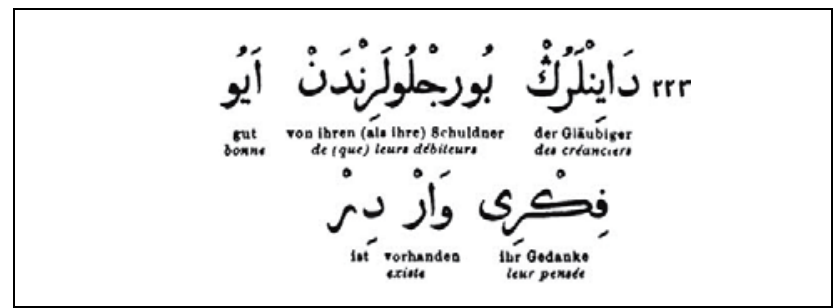

Dajínlerẏn bordschlulerindản ejú fikrí wảr dir. Dāïinleryñ bordjloulerindan eïu fikri vār dir. (222: 75) $\rightarrow$ /Dayinlerın dayinlerıñ borclulerindan eyü fikri vardir./ Fr. Les créanciers ont meilleure mémoire que leurs débiteurs. Alm. Gläubiger haben besseres Gedächtniss als ihre Schuldner.

154. Değirmen döner ama suyu nereden?

$$
\begin{aligned}
& \text { صوري } \\
& \text { "ב } \\
& \text { نرهن } \\
& \text { moher }
\end{aligned}
$$

Dejirmėn dönèr ảmma ßujú neredèn. Deïirmen deuner ammā soüou nereden. (227: 77) $\rightarrow$ /Deyirmen döner amma suyu nereden./ Fr. Le moulin tourne, mais d'où vient l'eau? Alm. Die Mühle dreht sich, aber woher das Wasser?

155. Deli alacayı sever.

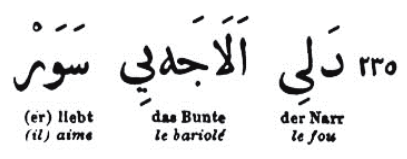

Delí aladschají sewèr. Deli alādjaïi sever. (235: 79) $\rightarrow$ /Deli alacayi sever./ Fr. Les fous aiment le bariolé. Alm. Narren lieben das Bunte.

156. Deli deliyi sever, danişment danişmendi sever.

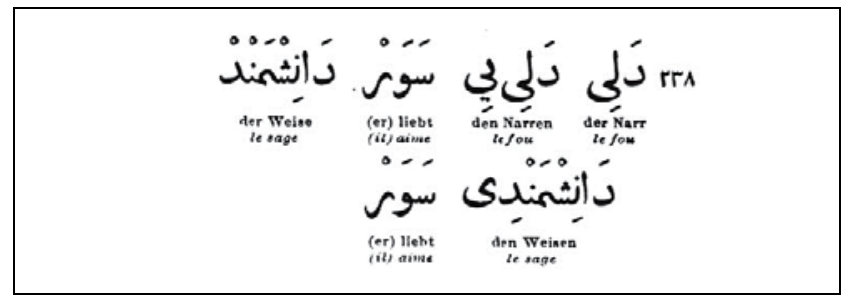

Delí delijí sewèr danischmènd danischmèndí sewèr. Deli delïi sever dānichmend dānichmendi sever. (238: 79) $\rightarrow$ /Deli deliyi sever danişmend danişmendi sever./ Fr. A leurs semblables s'attachent les fous et les sages (Qui se ressemble s'assemble). Alm. Der Narr liebt den Narren, der Gescheite den Gescheiten (Gleich und Gleich gesellt sich gern). 
157. Delinin yüreği ağzındadır, akilin dili yüreğindedir.

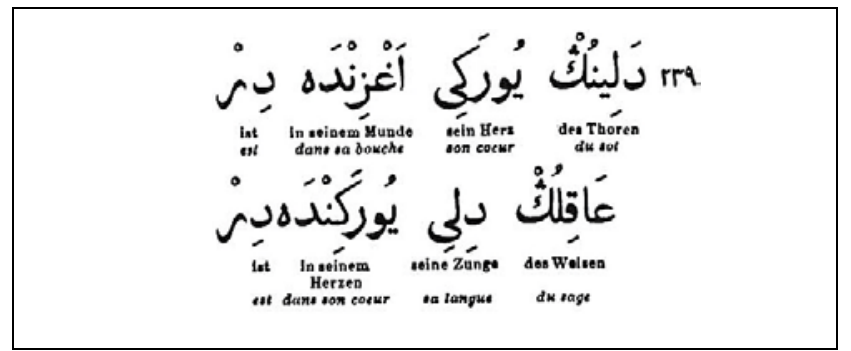

Delinẏn jürejí aghfindả dir akylỷn dilí jürejindėdir. Delinyñ üureïi aghzinda dir 'àqylyñ dili ïureïindedir. (239: 81) $\rightarrow$ /Delinın delinıñ yüreyi ağzindadir akılın 'âkılıñ dili yüreyindedir./ Fr. Le sot porte le coeur sur la langue, le sage a sa langue dans le coeur. Alm. Der Thor trägt sein Herz auf der Zunge, der Weise trägt die Zunge im Herzen.

158. Deli odur ki bir düştüğü çukura bir daha düşer.

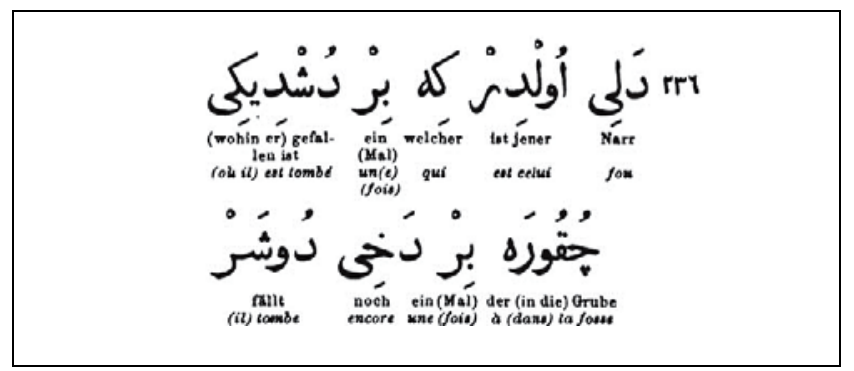

Delí òldir ki bir düschdigí tschukurả bir dahả (dachí) düschèr. Deli oldir ki bir duchdigui tchouqoura bir daha (dakhi) ducher. (236: 79) $\rightarrow$ /Deli oldir ki düşdiği çukura bir daha (dahi) düşer./ Fr. Bien fou qui tombe deux fois dans le même trou. Alm. Nur der Narr fällt zwei Mal in die selbe Grube.

159. Deli odur ki kendi söyler kendi işitir.

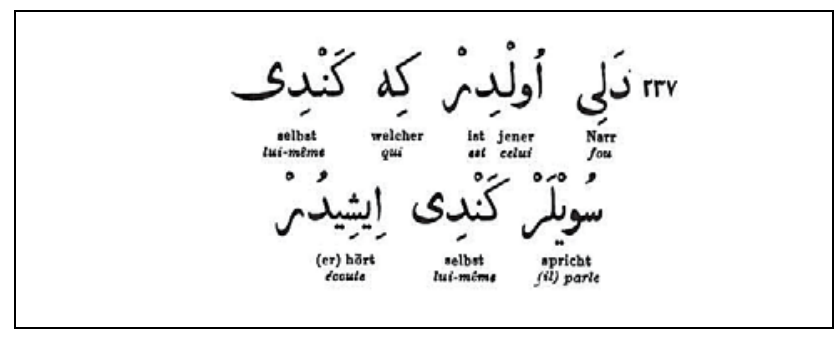

Delí òldir kí gendy் söjlèr gendy் ischidúr. Deli oldir ki guendy seuiler guendy ichidur. (237: 79) $\rightarrow$ /Deli oldir ki gendı söyler gendı işidür./ Fr. Fou est celui qui seul parle et seul s'écoute. Alm. Ein Narr ist, wer nur selbst spricht und nur sich selbst hört.

160. Denizde balık pazar olmaz.

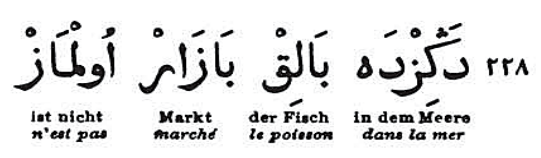

Denifdè balẏk bafảr olmảf. Deñizdè bālyq bāzār olmāz. (228: 77) $\rightarrow$ /Denizde deñizde 
balık bazar olmaz./ Fr. L'oisson dans l'eau ne se marchande pas. Alm. Den Fisch im Meere verhandelt man nicht.

161. Devletliye dokun geç, fukaradan sakın geç.

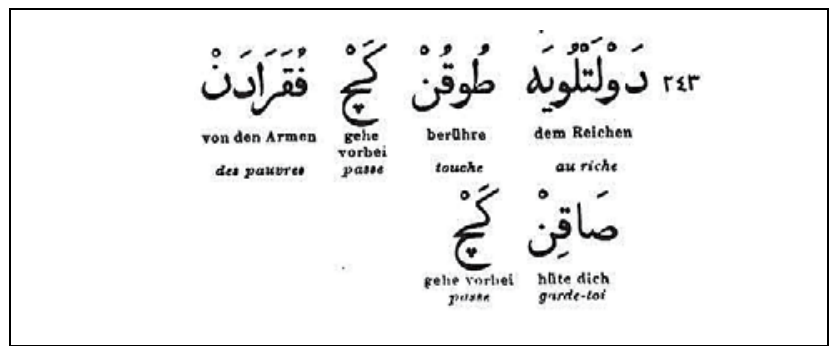

Dewletlüjè dhokún getsch fukaradản ßakỷn getsch. Devletluïè dhoqoun guetch fouqarādan sāqyn guetch. (243: 81) $\rightarrow$ /Devletlüye dokun geç fukaradan sakın geç./ Fr. Passe à côté du riche en l'effleurant, et à côté du pauvre, en l'évitant. Alm. Am Reichen streife gern, am Armen fern vorüber.

162. Dikenden gül biter gülden diken.

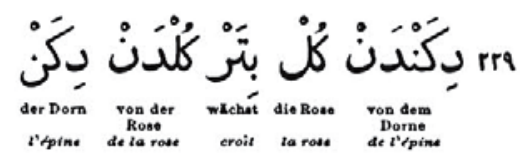

Dikendèn gül bitèr güldèn dikèn. Dikenden gul biter gulden diken. (229: 77) $\rightarrow$ /Dikenden gül biter gülden diken./ Fr. La rose naît de l'épine et l'épine de la rose. Alm. Aus dem Dorne wächst die Rose, aus der rose der Dorn.

163. Dil adamı beyan eder.

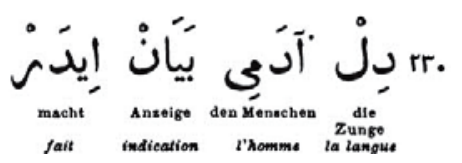

Dil adamí bejàn edèr. Dil âdami beīān eder. (230: 77) $\rightarrow$ /Dil adami beyan eder./ Fr. Le discours c'est l'homme. Alm. Wie die Zunge, so der Mensch.

164. Dilini zapt eden başını kurtarır.

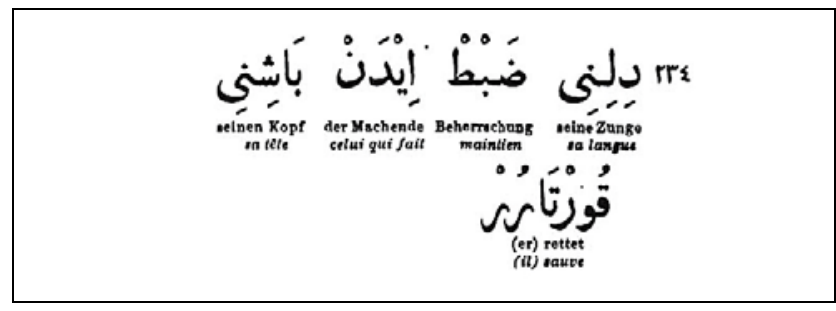

Diliní fảbth edèn baschiní kurtarúr. Dilini zabth eden bachini qourtārur. (234: 79) $\rightarrow$ /Dilini zabt eden başini kurtarür./ Fr. Qui retient sa langue sauve sa tête. Alm. Willst du den Kopf retten, halte den Mund. 
165. Dilin kemiği yoktur ama kemiği kırar.

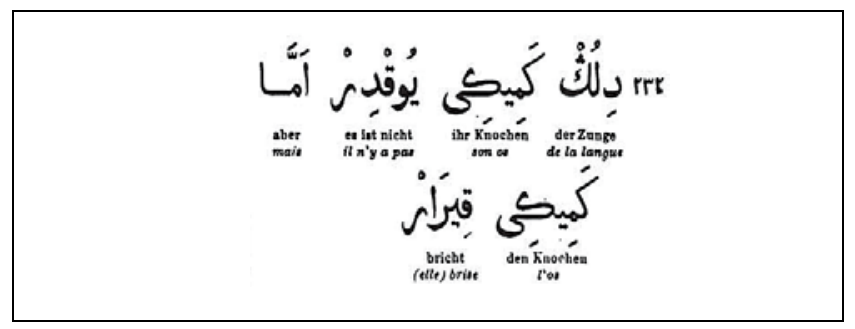

Dilỷn gemigí jỏkdir ảmma gemigí kyrảr. Dilyñ guemigui ïoqdir ammā guemigui qyrār. (232: 77) $\rightarrow$ /Dilın dilıñ gemiği yokdir amma gemiği kırar./ Fr. La langue n'a pas d'os, mais elle en brise. Alm. Die Zunge hat keine Knochen, aber sie zermalmt deren.

166. Dil kılıçtan çok öldürür.

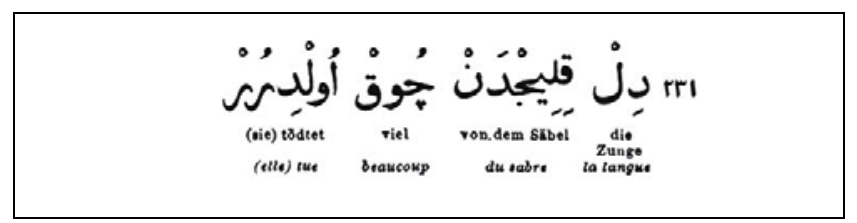

Dil kylidschdản tschok öldürǘr. Dil qylidjdan tchoq euldurur. (231: 77) $\rightarrow$ /Dil kılicdan çok öldürür./ Fr. La langue tue plus de gens que l'épée. Alm. Die Zunge tödtet mehr als das Schwert.

167. Dişin ağrıdığı yere dil dokunur.

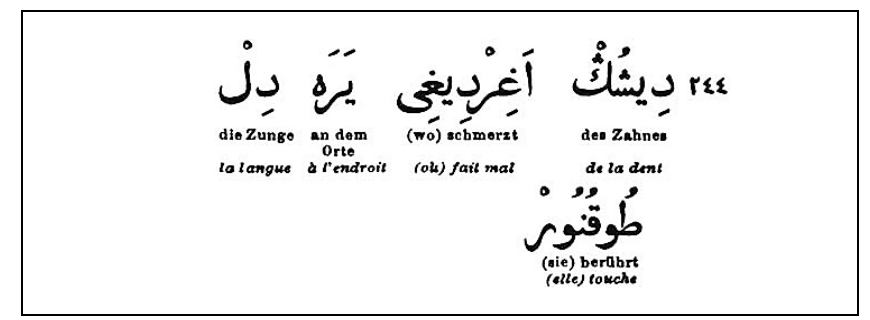

Dischẏn aghyrdijí jerè dil dhokunúr. Dichyñ aghyrdiïi ïerè dil dhoqounour. (244: 83) $\rightarrow$ /Dişın dişıñ ağırdiyi yere dil dokunur./ Fr. La langue se porte à la place où la dent fait mal. Alm. Wo der Zahn schmerzt, dorthin drückt die Zunge (Jeder weiss, wo ihn der Schuh drückt).

168. Doğru söyleyeni dokuz şehirden sürerler.

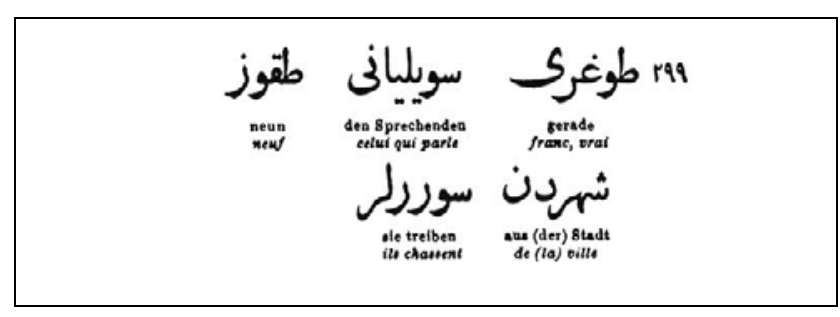

Dhoghrú söjlejení dhokúf schehirdèn sürerlèr. Dhoghrou seuileïeni dhoqouz chehirden surerler. (299: 99) $\rightarrow$ /Doğru söyleyeni dokuz şehirden sürerler./ Fr. Franc parleur est chassé de neuf villes. Alm. Wer offen spricht, den jagt man aus neun Städten. 
169. Doğru söz çok kimselere acı olur.

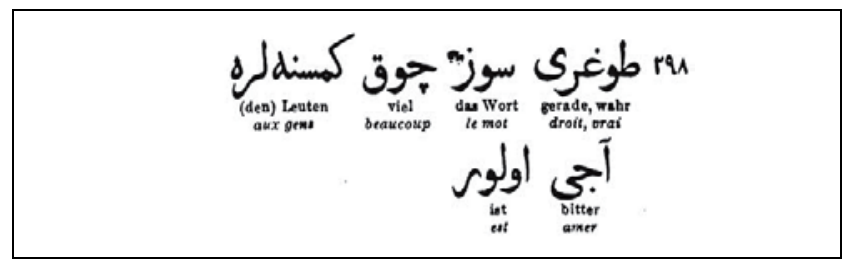

Dhoghrú söf tschỏk kimesnelerẻ adschí olúr. Dhoghrou seuz tchoq kimesnelerè âdji olour. (298: 97) $\rightarrow$ /Doğru söz çok kimesnelere aci olur./ Fr. Un mot sincère est pour beaucoup d'hommes une parole amère. Alm. Ein offenes Wort schmeckt Vielen bitter.

170. Dokuzu vermeyince onu kurtaramazsin.

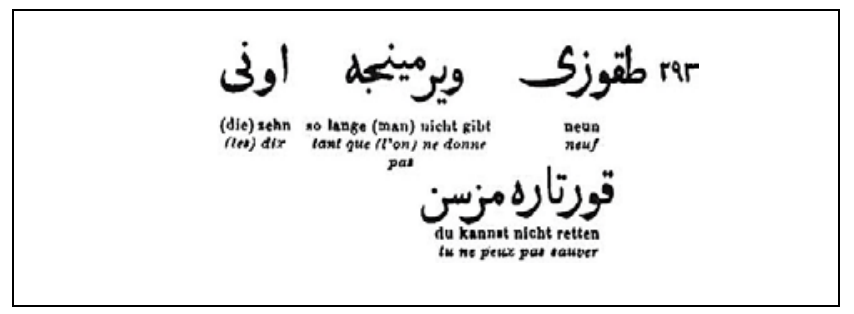

Dhokufú wėrmejíndsche onú kurtarảmafsin. Dhoqouzou vermeïindje onou qourtāramazsin. (293: 97) $\rightarrow$ /Dokuzu vermeyince onu kurtaramazsin./ Fr. Pour recouvrer un sur dir, il faut sacrifier neuf. Alm. Opferst du von zehn nicht neun, wird das Zehnte nimmer dein.

171. Domuzdan kıl koparmak hünerdir.

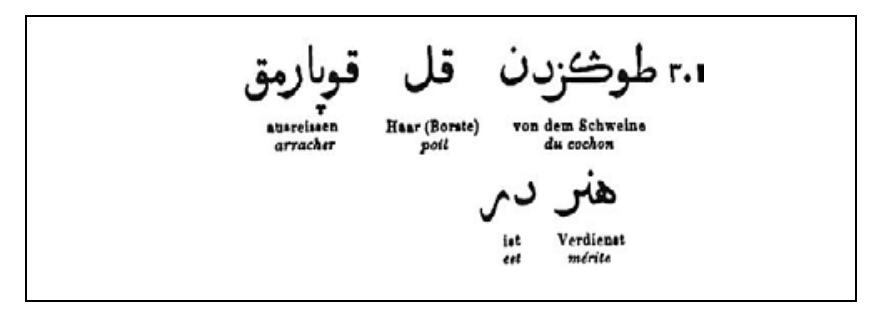

Dhomufdản (dhonufdản) kỷll koparmảk hünėr dir. Dhomouzdan (dhoñouzdản) qyll qopārmaq huner dir. (301: 99) $\rightarrow$ /Domuzdan (donuzdan doñuzdan) kıll koparmak hünerdir./ Fr. Il y a du mérite à arracher le poil au porc. Alm. Schweine rupfen ist ein Verdienst.

172. Domuz domuzu çalmaz.

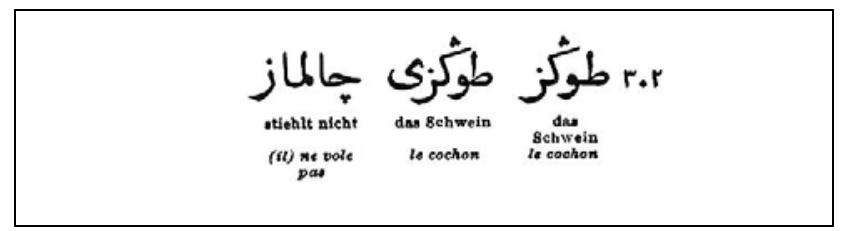

Dhomúf dhomufú tschalmảf. Dhomouz dhomouzou tchālmāz. (302: 99) $\rightarrow$ /Domuz domuzu çalmaz./ Fr. Un porc ne vole pas l'autre (Les loups ne se mangent pas les uns les autres). Alm. Ein Schwein stiehlt das andere nicht (Eine Krähe hackt der anderen die Augen nicht aus). 
173. Domuz gördüğünü çalar.

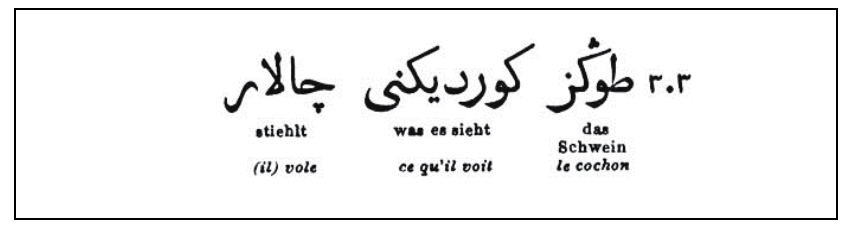

Dhomúf gördüginí tschalàr. Dhomouz gueurduguini tchālār. (303: 99) $\rightarrow$ /Domuz gördüğini çalar./ Fr. Le porc vole ce qu'il voit. Alm. Das Schwein stiehlt was es sieht.

174. Dosta çok varan ekşi surat görür.

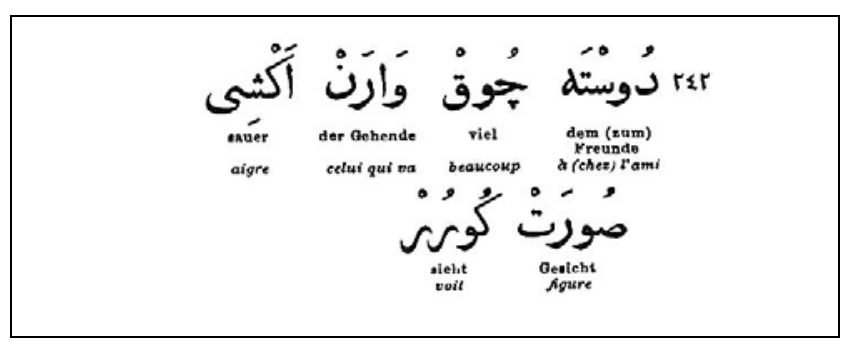

Dostả tschỏk warản ekschí ßurèt görúr. Dosta tchoq vārān ekchi souret gueurur. (242: 81) $\rightarrow$ /Dosta çok varan ekşi suret görür./ Fr. Visite trop fréguente ne trouve pas mine riante. Alm. Willst du gelten mach' dich selten.

175. Dost bin ise azdır, düşman bir ise çoktur.

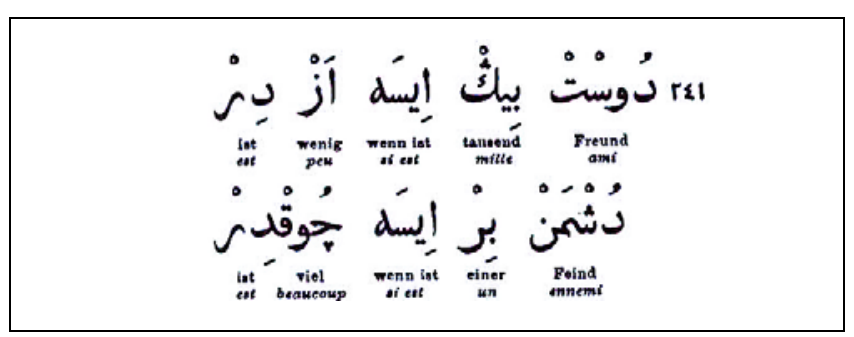

Dost bín isè àf dir düschmèn bir isẻ tschỏkdir. Dost bîn içè az dir duchmen bir içè tchoqdir. (241: 81) $\rightarrow$ /Dost bin biñ ise azdir düşmen bir ise çokdir./ Fr. Mille amis c'est peu; un ennemi c'est beaucoup. Alm. Tausend Freunde sind wenig; Ein Feind ist viel.

176. Dünya tükenir, düşman tükenmez.

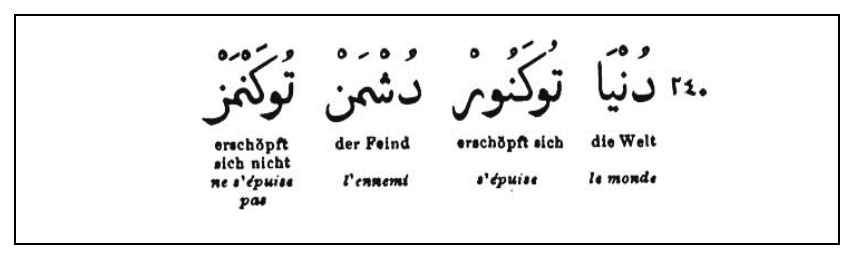

Dünjả tükenúr düschmèn tükenmèf. Dunäā tukenur duchmen tukenmez. (240: 81) $\rightarrow$ /Dünya tükenür düşmen tükenmez./ Fr. Tout finit ici-bas hors l'inimitié. Alm. Die Welt hört auf, die Feindschaft nicht. 
177. Düşman düşmanın hâlinden bilmez.

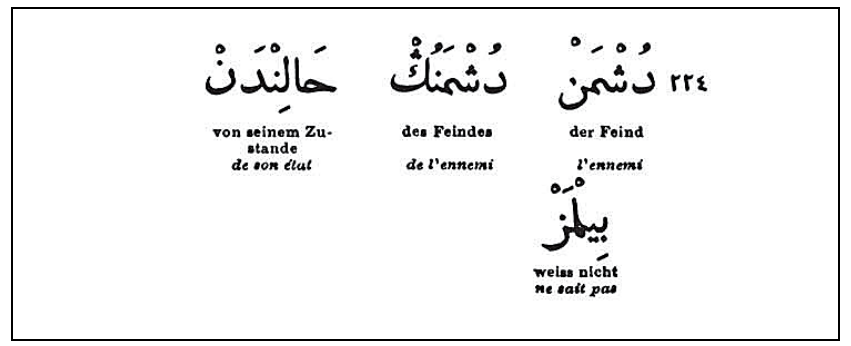

Düschmėn düschmenỷn halindản bilmèf. Duchmen duchmenyñ hālindan bilmez. (224: $75) \rightarrow$ /Düşmen düşmenın düşmenıñ halindan bilmez./ Fr. L'ennemi est mauvais juge de son ennemi. Alm. Kein Feind beurtheilt richtig séinen Feind.

178. Düşman karınca ise fil gibi san.

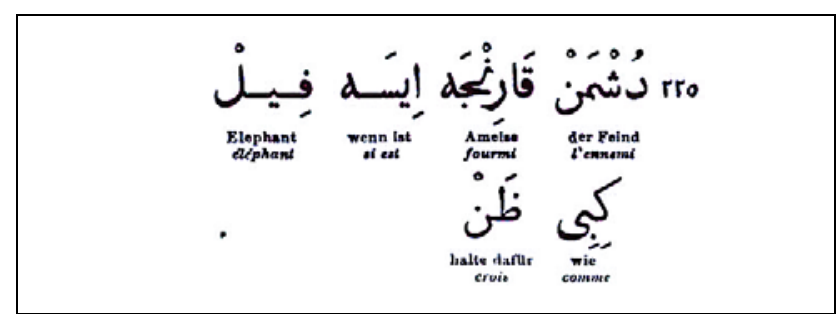

Düschmèn karindschả isė fíl gibú fảnn. Duchmen qarindja içè fîl guibi zann. (225: 75) $\rightarrow$ /Düşmen karinca ise fil gibi zann./ Fr. Ton ennemi ne fût-il qu'une fourmi, vois en lui un éléphant. Alm. Wäre dein Feind eine Ameise, du halte ihn für einen Elephanten.

179. Edepli edepsizden edep öğrenir.

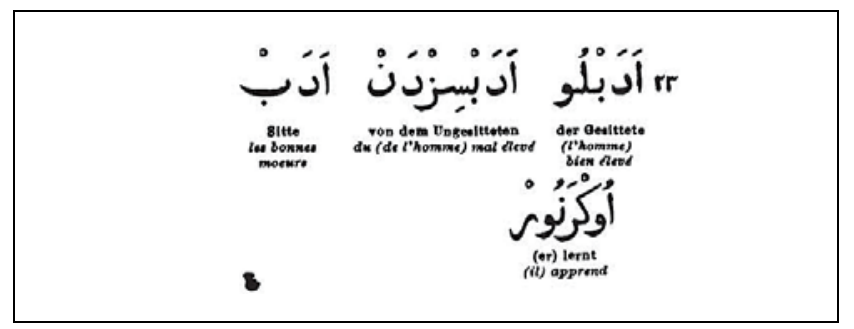

Edeblú edebsyfdèn edèb öjrenúr. Edeblu edebsyzden edeb euirenur. (23: 11) $\rightarrow$ /Edeblü edebsizden edeb öyrenür./ Fr. Les bonnes moeurs s'apprennent des mauvaises. Alm. Sitte lernt man von der Unsitte.

180. Efendinin nazarı ata tımardır.

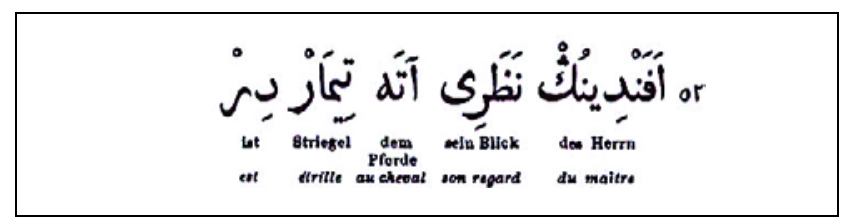

Efendinẏn nafarí atả timảr dir. Efendinyñ nazari âta tîmār dir. (52: 19) $\rightarrow$ /Efendinın efendinıñ nazari ata timardir./ Fr. L'oeil du maître esl l'étrille du cheval. Alm. Das Auge des Herrn ist der Striegel des Pferdes. 
181. Eğreti ata binen tez iner.

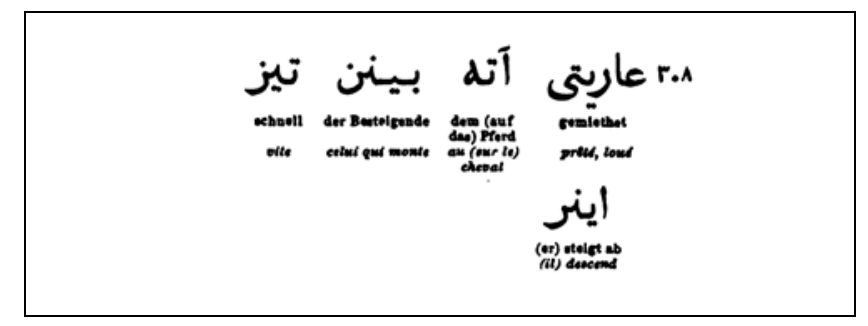

Arietí atả binèn tíf inèr. 'Āriéti âta binen tîz iner. (308: 101) $\rightarrow$ /Aryeti âryeti (?) ata binen tiz iner./ Fr. De cheval loué on descend bientôt. Alm. Vom ausgeliehenen Gaul steigt man bald ab.

182. Eğri otur, doğru söyle.

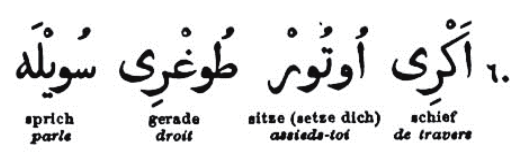

Ejrí otúr dhoghrú söjlè. Èïri otour dhoghrou seuilè. (60: 21) $\rightarrow$ /Eyri otur doğru söyle./ Fr. Ayez le maintien gauche, pourvu que votre langage soit droit. Alm. Sitze schief, doch sprich gerade.

183. Ekmeği yalnız yiyen yükünü kendi kaldırır.

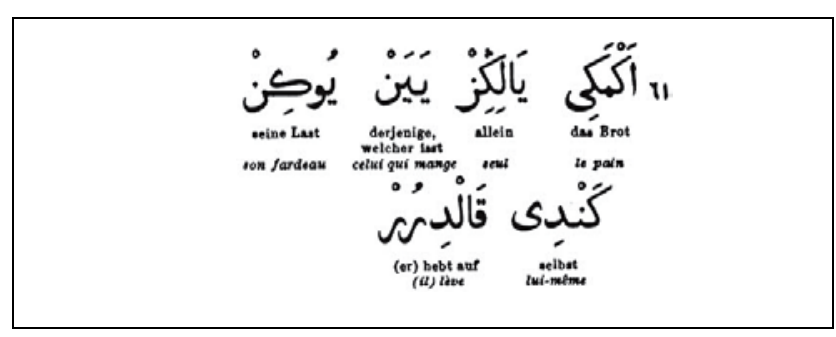

Ekmejí jalynẏf jejèn jükín gendỷ kaldyrûr. Ekmeïi īālyñyz ïeïen ïukin guendy qāldyrur. (61: 21) $\rightarrow$ /Ekmeyi yalnız yalñız yeyen yükin gendı kaldırür./ Fr. Qui mange seul son morceau porte aussi seul son fardeau. Alm. Wer sein Brot allein isst, trägt auch seine Last allein.

184. El ayıbın söyleyen senin aybını da söyler.

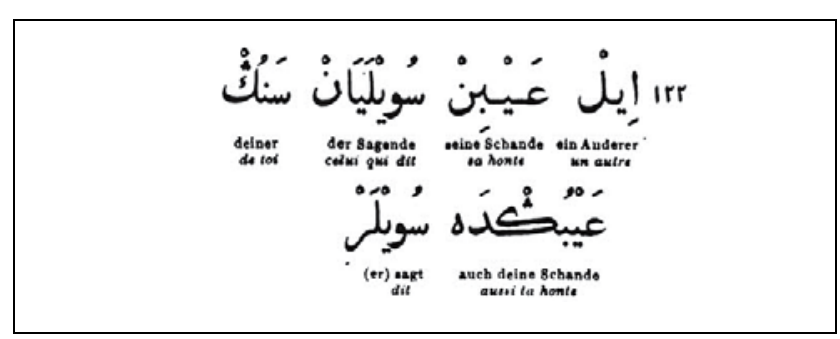

İl aibín söjlejèn senẏn aibỷnda söjlèr. İl 'aïbin seuileïen senyñ 'aïbyñda seuiler. (122: 41) $\rightarrow$ /İ aybin 'aybin (?) söyleyen senın senıñ aybın (?) da 'aybıñ (?) da söyler./ Fr. Mèdira de toi qui mèdit des autres. Alm. Wer die Fehler Anderer rügt, rügt auch die deinen. 
185. Elden çıkan ele gelmez.

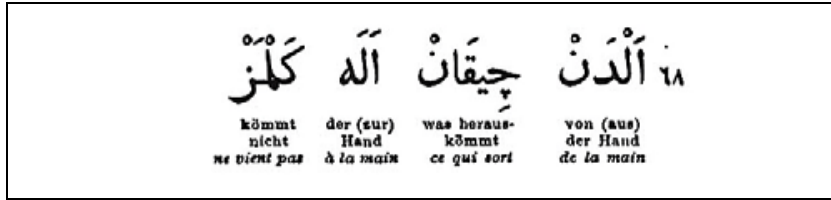

Eldèn tschykản elè gelmèf. Elden tchyqān elè guelmez. (68: 23) $\rightarrow$ /Elden çıan ele gelmez./ Fr. Occasion perdue ne se présente plus. Alm. Entgangenes kehrt nicht wieder.

186. El eli yur, iki el yüzü yur.

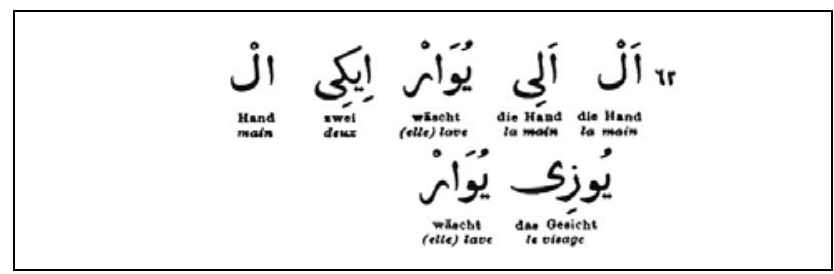

El elí juwảr ikí el jüfí juwảr. El eli ïouvār iki el ïuzi ïouvār. (62: 21) $\rightarrow$ /El eli yuvar iki el yüzi yuvar./ Fr. Une main lave l'autre, les deux mains lavent la figure. Alm. Eine Hand wäscht die andere, beide waschen das Gesicht.

187. El için ağlayan gözsüz kalır.

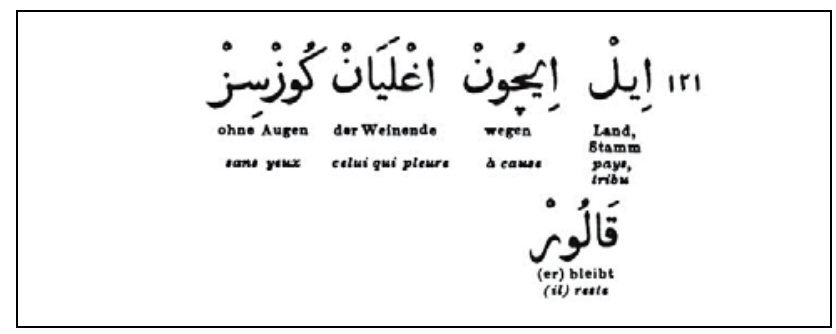

íl itschû́n aghlajản göfsẏf kalû́r. İl itchun aghlaīān gueuzsyz qālur. (121: 41) $\rightarrow$ /İl içün ağlayan gözsız kalür./ Fr. Qui pleure sur tout le monde finit par perdre la vue. Alm. Wer um alle Welt weint, wird am Ende blind.

188. Elma kendi ağacından ırak düşmez.

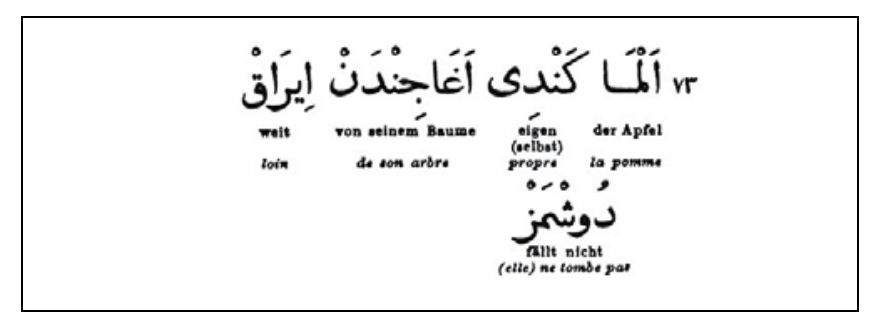

Elmả gendỷ aghadschindản irảk düschmèf. Elmā guendy aghādjindan irāq duchmez. (73: 25) $\rightarrow$ /Elma gendı ağacindan irak düşmez./ Fr. La pomme ne tombe pas loin de l'arbre (Bon sang ne peut mentir). Alm. Der Apfel fällt nicht weit vom Stamm. 
189. Epsem olmak çok söylemekten yeğdir.

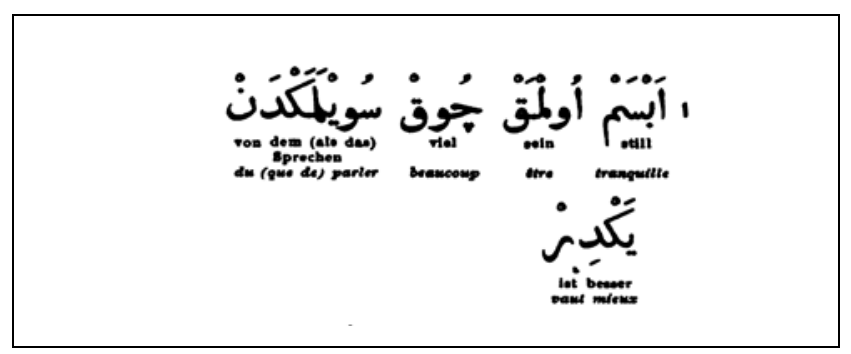

Ebsém olmák tschok söjlemekdén jékdir. Ebsem olmaq tchoq seuilemekden ïekdir. (1:3) $\rightarrow$ /Ebsem olmak çok söylemekden yekdir./ Fr. Mieux vaut se taire que trop parler. Alm. Besser schweigen als zü viel reden.

190. Erkek ondan dokuzu zendir.

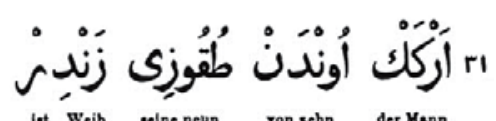

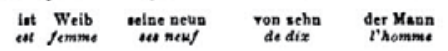

Erkèk ondản dhokufú fẻndir. Erkek ondan dhoqouzou zendir. (31: 13) $\rightarrow$ /Erkek ondan dokuzu zendir./ Fr. Sur dix hommes neuf sont femmes. Alm. Von zehn Männern sind neun Weiber.

191. Er olan ekmeğin taştan çıkarır.

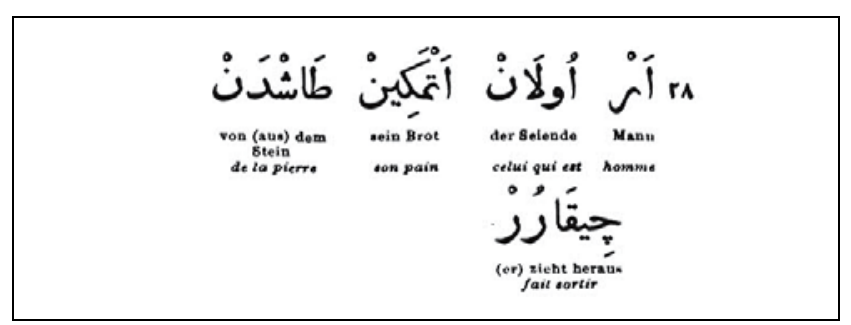

Ėr olản etmejín (ekmejín) thaschdản tschykarúr. Er olān etmeïin (ekmeïin) thāchdān tchyqārur. (28: 11) $\rightarrow$ /Er olan etmeyin (ekmeyin) taşdan çıarür./ Fr. L'homme énergique tire son pain même du rocher. Alm. Der wahre Mann weiss auch aus Stein sein Brot herauszuschlagen.

192. Erteye kalan kazadan korkma.

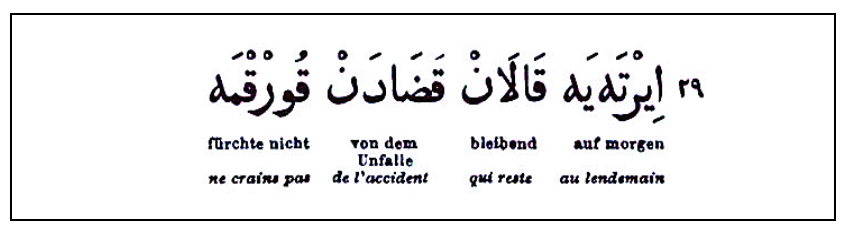

Ertejè kalản kafadản kỏrkma. Erteïè qālān qazādan qorqma. (29: 13) $\rightarrow$ /Erteye kalan kazadan korkma./ Fr. Ne redoute pas l'accident du lendemain. Alm. Vor dem morgigen Unheile fürchte dich nicht. 
193. Eski samanları karıştırma.

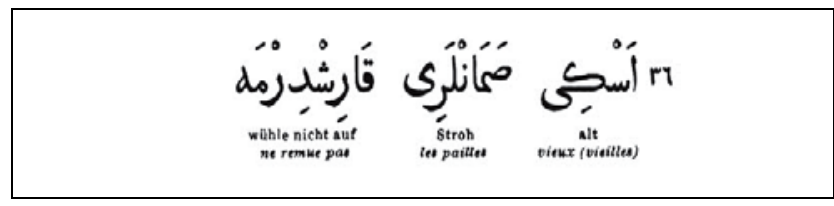

Eskí ßamanlerí karyschdírma. Eski samānleri qārychdirma. (36: 13) $\rightarrow$ /Eski samanleri karışdirma./ Fr. Ne remue pas le vieille paille. Alm. In altem Stroh wühle nicht.

194. Eski süpürgeyi dama atarlar.

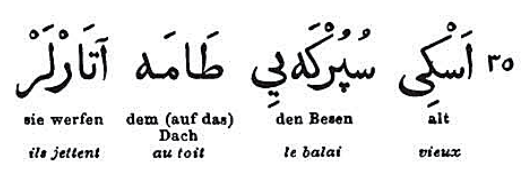

Eskí süpürgejí dhamả atarlảr. Eski supurgueïi dhāma âtārlar. (35: 13) $\rightarrow$ /Eski süpürgeyi dama atarlar./ Fr. Les vieux balais se jettent au grenier. Alm. Alte Besen wirft man auf's Dach.

195. Eski yâr, eski hamam.

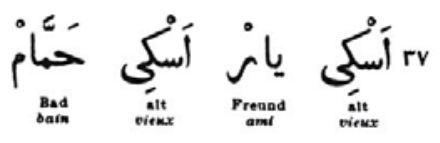

Eskí jar eskí hammảm. Eski īār eski hammām. (37: 15) $\rightarrow$ /Eski yar eski hammam./ Fr. Vieil ami, vieux bain (On n'aime changer ni l'un ni l'autre). Alm. Ein alter Freund, ein altes Bad (Beide wechselt man ungern).

196. Eşeğe semeri yük değil.

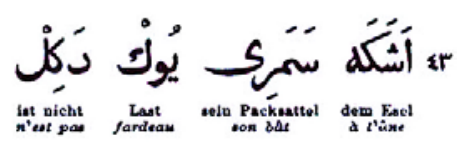

Eschejè semerí jük dejíl. Ècheïè semeri ïuk deïil. (43: 17) $\rightarrow$ /Eşeye semeri yük deyil./ Fr. Le bût ne pèse point à l'âne. Alm. Dem Esel ist sein Sattel keine Last.

197. Eşeğin anırmazı olmaz.

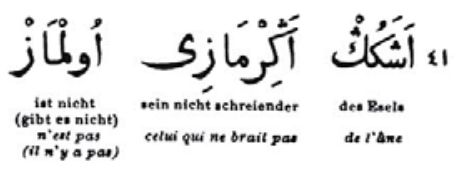

Eschegẏn anyrmafí olmảf. Èchegyñ añyrmāzi olmāz. (41: 15) $\rightarrow$ /Eşeğin eşeğiñ anırmazi añırmazi olmaz./ Fr. Il n'est d'âne qui ne braie. Alm. Keil Esel, der nicht iat. 
198. Eşeğini evvel bağla, sonra Tanrı'ya ısmarla.

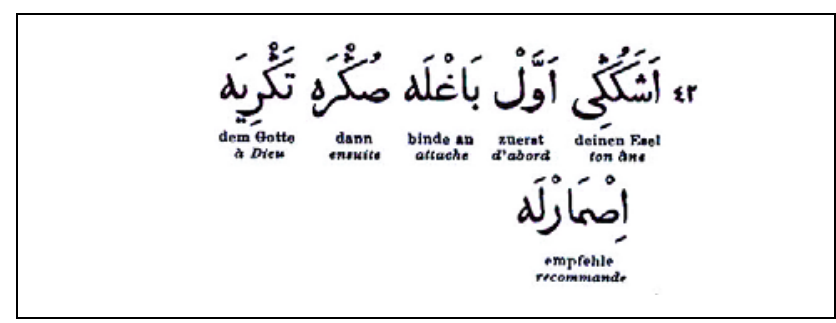

Eschegyní ewwèl baghlả ßòñra tañrijả yßmarlả. Èchegyñi evvel bāghla soñra tañriïa ysmārla. (42: 15) $\rightarrow$ /Eşeğıni eşeğıñi evvel bağla soñra Tañri'ya ısmarla./ Fr. Attache d'abord ton âne, ensuite tu le recommanderas à Dieu. Alm. Erst binde deinen Esel fest, dann empfehle Gott den Rest.

199. Eşek dağda ölür, zararı eve gelir.

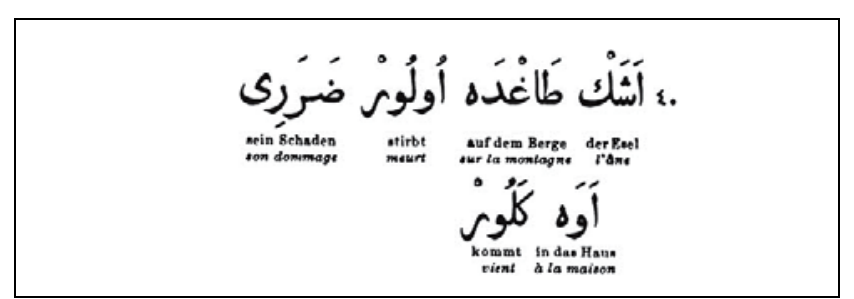

Eschèk dhaghdả ölúr fararỷ ewė gelúr. Èchek dhāghda eulur zarary èvè guelur. (40: 15) $\rightarrow$ /Eşek dağda ölür zararı eve gelür./ Fr. L'âne meurt au pâturage, la maison en éprouve le dommage. Alm. Der Esel stirbt auf den Weiden, das Haus muss den Schaden leiden.

200. Et ile tırnak arasına girme.

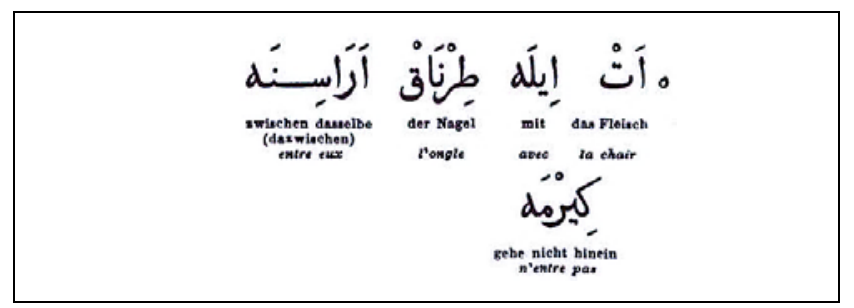

Et ilè thyrnảk arasinả gírme. Et ilè thyrnāq arāçina guirmè. (5:3) $\rightarrow$ /Et ile tırnak arasina girme./ Fr. N'entre pas entre l'ongle et la chair. Alm. Dränge dich nicht zwischen Nagel und Fleisch.

\section{SONUÇ}

Makalede bir transkripsiyon metni olan Osmanische Sprichwörter'deki 100 (101-200 arası) atasözü üzerinde durulmuştur. Eserde atasözlerinin Arap harfli metinleri yanında Latin harflerinin kullanılması bizler için sözcük ve eklerin telaffuzlarına dair birtakım bilgiler vermektedir.

Buna göre telaffuzla ilgili olarak şu sonuçlara varmak mümkündür.

1. Dil ve dudak uyumuna aykırılıklar [alacayi (155), edebsızden (179), ermağani (135), halindan (177), samanlari (193); eyü (153), gelür (199), işidür (159), yükin (183) vb.], ünsüz uyumuna aykırılıklar [karışdirma (193), kılicdan (166), kudurmuşdan (149), söylemekden (189), uzakdan (152) vb.] eserdeki konuşma dilinin önemli özellikleri arasındadır.

2. İyelik üçüncü teklik kişi ve yükleme durumu eklerinin uyum dâhilinde telaffuz edildiği 
görülmektedir: budunu (112), kuzusu (140), oğlu (131), onu (170), suyu (154). Buna karşın: gözi (147).

3. Dağ $(145,146,148,199)$, dam (194), danışan (148), darıl- (149), doğru $(168,169,192)$, dokun(161, 167), dokuz (113, 168, 170), duman (145), dur- (117) gibi sözcüklerdeki ilk ünsüzler b ile yazilmakta fakat $/ \mathrm{d} /$ ile telaffuz edilmektedirler.

4. Ağırdiyi (167), bey (116), deyil (124, 145, 196), deyirmen (154), ekmeyi (183), eşeye (196), eyri (182), öyrenür (179), yiyit (145), yüreyi (157), yüreyindedir (157) gibi sözcüklerdeki işaretli ünsüzler s ile yazılmakta ama akıcılaşarak /y/ ile telaffuz edilmektedir. Buna karşın: düşdiği (158), eşeğin eşeğiñ (197), gördü̈̆ini (173).

5. Baklanın (144), başın (123), canın (127), cimrinın (131), delinın (157), dilın (165), insanın (139) gibi sözcüklerde ilgi durumu eki ötre ile yazılmasına rağmen dudak uyumu dâhilinde yani düz ünlü ile telaffuz edilmektedir. [Fransız transkripsiyon sisteminde ilgi durumu ekinin son ünsüzünün nazal olarak telaffuz edildiği belirtilmiştir: baklaniñ (144), başı̃ (123) gibi.]

6. Irte, it- ve vir- sözcükleri et- $(163,164)$, erte (192). ver- (170) biçiminde telaffuz edilmektedir.

7. Ur- biçiminde yazılmasına rağmen telaffuz vur- $(113,114)^{\prime}$ tır.

8. Gemiği (165), gendı (159, 183, 188) sözcüklerinin ilk ünsüzleri tonlu olarak telaffuz edilmektedir.

9. لب biçiminde yazılan davul sözcügü taul $(152,153)$ ve tabl $(152)$ şeklinde ikili telaffuza sahiptir. دَخِّö̌üğü daha (158) ve dahi (158) biçimlerinde telaffuz edilebilmektedir.

10. Domuz sözcüğü üç noktalı Sile yazılmasına karşın hem /m/ [domuz $(171,172)]$ hem de /n/ ile [donuz (hatta doñuz) $(171,172)]$ telaffuz edilmektedir.

11. Kocakla- (141) sözcüğünün ilk ünlüsü geniş olarak telaffuz edilmektedir.

12. Daima ve yeğ sözcükleri dayma (125) ve yek $(101,116,120,189)$ biçiminde telaffuz edilmektedir.

13. Eserde vakit sözcüğünün hem türemiş art bir ünlüyle hem de ünlü türemesi olmadan telaffuz edildiği kaydedilmiştir: vakıtsız (vaktsız) (126).

\section{SUMMARY}

The term "transcription texts" is used in Turkology to refer to Turkish texts written in alphabets other than Arabic (such as Latin, Greek, Armenian, Syrian, Hebrew, Cyrillic). Much as György Hazai objected to the term and put forward that the expression of "Non-Arabic monuments" would be more appropriate, the terms "transcription texts" or "transcription monuments" have now been established.

Transcription texts are quite "heterogenous". They were written using different alphabets by people with dissimilar language, culture and knowledge. Since the early 1900s, transcription texts studied especially by the Europeans attracted the attention of Turkish researchers and as a result numerous studies were carried out on these texts by the Turks. The transcription text we examined here is Osmanische Sprichwörter. The words in Osmanische Sprichwörter were given in Latin letters as well, so that the Germans and the French could read them. It enabled Turkish language researchers to see pronunciations that orthography may have obstructed in many words and appendices.

It would not be incorrect to state that Ottoman script was mostly conservative and traditional. Therefore, it is quite difficult to trace the phonetic developments of the language via standard writing. Turkish language underwent changes and developments through both Turkish and borrowed foreign words, however Ottoman orthographic system rendered the relationship between written and spoken forms of the language incomprehensible. In this context, transcription texts that reveal the sounds of the Turkish language are very beneficial since they contain "spoken Turkish". 
In this study, 100 (101 to 200) proverbs from Osmanische Sprichwörter were evaluated.

Osmanische Sprichwörter was published in 1865 by students M. Pasetti Ritter Von Friedenburg, A. Rehn, A. Bargehr, J. Günner, E. Von Sauer-Czaky-Nordendorf, E. Trechich ve director Ottokar Maria Freiherr von Schlechta-Wssehrd of K. K. Orientalische Akademie In Wien. It was stated in the preface that the proverbs in the texts were based on a manuscripts collection prepared by two former Akademie students and a manuscript by Güvahi.

There are a total of 500 proverbs in Osmanische Sprichwörter. The proverbs were written in Ottoman alphabet. Vowel points were used only for the first 250 proverbs and omitted for the rest. It was stated in the preface that the idea of "a transition from easy to difficult" was instrumental in that decision since the aim of the book was to teach Turkish language to the Germans and the French. As per the book, the writers preferred a middle ground and strived to both be faithful to the "oriental script", i.e. conventional orthography, and give the pronunciations. In fact, it was especially emphasized in the book that more importance was placed on pronunciation.

Another aim of Osmanische Sprichwörter was to offer the means to overcome the initial difficulties of reading and understanding Ottoman texts for the Germans and the French without needing a teacher. In addition, the same ease was meant for the Turks who wished to improve themselves in terms of German and French texts. In order to fulfill this double task, the simplest possible texts were chosen and proverbs were thought to fit the bill in that regard. Proverbs are succinct and offer advantages in terms of both the grammar and the culture and traditions.

There are some additions to Ottoman text in Osmanische Sprichwörter:

Interlinear Translation (German and French): German and French translations of the proverbs were given word by word under the Ottoman text. The aim was to be able to study without the need for a teacher. It is interesting that it was noted in the preface that this method, used commonly and successfully in other laguages, was applied to the Western Turkish on a larger scale for the first time (?).

Pronunciation: In Osmanische Sprichwörter, proverbs were presented with pronunciations, as well as Ottoman letters. Two distinct transcription systems were used for German and French. It should be noted that the transcription of pronunciations of proverbs were tried to be adapted to the language and tone of voice as closely as possible used in "the best circles of the Muslim society" of Istanbul.

A German and French Translation: Here, German and French translations of the proverbs were given. Sometimes a proverb used in German or French with the same meaning was given as a translation.

Glossary: A glossary was placed at the end of Osmanische Sprichwörter.

The proverbs in Osmanische Sprichwörter: In this study, 100 (101 to 200) proverbs from Osmanische Sprichwörter were given. They were ordered alphabetically according to their present-day forms and were presented with the information provided in the diagram at the beginning of the article.

Teaching of the Turkish language is one of the fundemental aims of the Osmanische Sprichwörter. In addition to that, the book reveals spoken language through proverbs. Therefore, it provides useful information about phonological features of the era it was written. That being said, there are some significant features of the spoken language in the book; namely, contradictions to consonant harmony, disregard for consonant harmony in some affixes, sonorisations. 


\section{KAYNAKÇA}

Bekâr, B. (2019). Batı kültüründe Türk atasözleri (16. yüzyll-19. yüzyll). Konya: Kömen Yay.

Böler, T. (2018). Osmanische Sprichwörter (1865) adlı eserdeki Türk atasözleri ve bu atasözlerinin telaffuzu. V. Yıldız Uluslararası Sosyal Bilimler Kongresi Tam Metin Bildiri Kitabı içinde (s. 850-865), İstanbul: Yıldız Teknik Üniversitesi Yay.

Duman, M. (1999). Klasik Osmanlı Türkçesi döneminde i/e meselesine dair. İlmî Araştırmalar, 7, 65103.

Hazai, G. (2012). Türkiye Türkçesinin dünü ve bugünü (T. Turan, Çev.). Ankara: Türk Dil Kurumu Yay. K. K. Orientalische Akademie (1865). Osmanische sprichwörter. Wien: K.K. Hof- und Staats-Druckerei. Kartallığlu, Y. (2011). Klasik Osmanlı Türkçesinde eklerin ses düzeni (16, 17 ve 18. yüzyıllar). Ankara: Türk Dil Kurumu Yay.

Tulum, M. (1991). Alfabe ve alfabemiz üzerine. Dil ve alfabe üzerine görüşler içinde (s. 23-27). Ankara: Atatürk Kültür, Dil ve Tarih Yüksek Kurumu Yay. 